\title{
Strategic party formation on a circle
}

Citation for published version (APA):

Peeters, R. J. A. P., Saran, R. R. S., \& Yüksel, A. M. (2010). Strategic party formation on a circle.

METEOR, Maastricht University School of Business and Economics. METEOR Research Memorandum No. 045 https://doi.org/10.26481/umamet.2010045

Document status and date:

Published: 01/01/2010

DOI:

10.26481/umamet.2010045

Document Version:

Publisher's PDF, also known as Version of record

\section{Please check the document version of this publication:}

- A submitted manuscript is the version of the article upon submission and before peer-review. There can be important differences between the submitted version and the official published version of record.

People interested in the research are advised to contact the author for the final version of the publication, or visit the DOI to the publisher's website.

- The final author version and the galley proof are versions of the publication after peer review.

- The final published version features the final layout of the paper including the volume, issue and page numbers.

Link to publication

\footnotetext{
General rights rights.

- You may freely distribute the URL identifying the publication in the public portal. please follow below link for the End User Agreement:

www.umlib.nl/taverne-license

Take down policy

If you believe that this document breaches copyright please contact us at:

repository@maastrichtuniversity.nl

providing details and we will investigate your claim.
}

Copyright and moral rights for the publications made accessible in the public portal are retained by the authors and/or other copyright owners and it is a condition of accessing publications that users recognise and abide by the legal requirements associated with these

- Users may download and print one copy of any publication from the public portal for the purpose of private study or research.

- You may not further distribute the material or use it for any profit-making activity or commercial gain

If the publication is distributed under the terms of Article $25 \mathrm{fa}$ of the Dutch Copyright Act, indicated by the "Taverne" license above, 


\section{Maastricht University}

Ronald Peeters, Rene Saran, Ayşe Müge Yüksel

Strategic Party Formation on a Circle

$\mathrm{RM} / 10 / 045$

\section{METEOR}

Maastricht University School of Business and Economics

Maastricht Research Schocl of Economics

of Technology and Organization

PO. Box 616

NL - 6200 MD Mastricht

The Netherlands 


\title{
Strategic Party Formation on a Circle*
}

\author{
Ronald Peeters $^{\dagger} \quad$ Rene Saran ${ }^{\ddagger} \quad$ Ayşe Müge Yüksel ${ }^{\S}$
}

September 2010

\begin{abstract}
We study a spatial model of party formation in which the set of agendas is the unit circle. We characterize the sets of pure-strategy Nash equilibria under the plurality and proportional rules. In both rules, multiple configurations of parties are possible in Nash equilibrium. We refine our predictions using a new notion called "defection-proof" Nash equilibrium. Under the plurality rule, only those Nash equilibria in which either two or three parties exist are defection-proof, whereas multiple parties exist in any defectionproof Nash equilibrium under the proportional rule. These results are mostly consistent with the predictions of Duverger (1954).

Keywords: Party Formation; Spatial Model; Plurality Rule; Proportional Rule; Nash Equilibrium; Defection-Proof Nash Equilibrium.
\end{abstract}

JEL Classification Numbers: C72; D72.

\section{Introduction}

In democratic societies, collective decisions are made in legislatures. The legislators are often grouped into parties. Party representation and configuration in turn depend on the political framework (cf. Rae, 1971; Lijphart, 1990 and Taagepera and Shugart, 1989) and the particular strategies adopted by the politicians, parties and voters within that framework. One natural question is, how electoral systems affect the number of parties that form and their respective positions?

Two famous predictions about the effect of electoral systems on political party formation are attributed to the political scientist, Maurice Duverger (1954). Duverger's law states that plurality voting favors a two-party system. According to Duverger's hypothesis, proportional representation favors multi-partyism. Therefore, the Duvergerian comparative prediction is

\footnotetext{
${ }^{*}$ We thank Eric Maskin, Kaj Thomsson and the participants of the 21st Jerusalem School in Economic Theory on Political Economy for useful comments and suggestions.

${ }^{\dagger}$ Department of Economics, Maastricht University, PO Box 616, 6200 MD Maastricht, The Netherlands. Email: r.peeters@maastrichtuniversity.nl

${ }^{\ddagger}$ Department of Economics, Maastricht University, PO Box 616, 6200 MD Maastricht, The Netherlands. Email: r.saran@maastrichtuniversity.nl

${ }^{\S}$ Department of Economics, Maastricht University, PO Box 616, 6200 MD Maastricht, The Netherlands. Email: a.yuksel@maastrichtuniversity.nl
} 
that the number of parties is larger under proportional representation than under plurality voting (Riker, 1982; Morelli, 2004).

Cox (1987), Palfrey (1989), Feddersen (1992) and Fey (1997) find theoretical support for Duverger's law when the voters avoid wasting their vote on "hopeless" candidates. Rivière (1998), and Osborne and Tourky (2008) focus on economies of party size to explain the formation of political parties. Other papers that explain the existence of parties, without particularly focusing on one of Duverger's predictions, include Osborne and Slivinski (1996), Besley and Coate (1997), Jackson and Moselle (2002), Snyder and Ting (2002), and Levy (2004).

Morelli (2004) is the first to addresses both the law and hypothesis. He shows that more than two parties may be active in a multi-district election with plurality voting when there is sufficient heterogeneity in policy preferences across districts. In addition, when the distribution of preferences is more aligned, the number of "effective" parties under proportional representation must be less than three. Thus, Morelli (2004) finds that the Duvergerian comparative prediction may be violated in a multi-district setting.

In this paper, we study whether the predictions by Duverger have game theoretic foundations in a spatial model. ${ }^{1}$ The Downsian model of electoral competition (Downs, 1957), where the set of agendas equals the unit interval, is not suitable for this research. In this standard framework, pure-strategy equilibria do not exist under the proportional rule; whereas, the incentive to attract the median voter generates a single party in the pluralistic system when considering refinements that allow movements on party-level. This motivates our point of departure from the standard framework: we instead assume that the set of agendas equals the unit circle. We hereby follow in the success of the industrial organization literature in studying multi-firm competition by moving from Hotelling's linear city (Hotelling, 1929) to Salop's circular city (Salop, 1979). ${ }^{2}$

The summary description of the model is as follows. There are a finite number of politicians that simultaneously and independently choose to promote agendas in the elections, where the set of agendas is the unit circle. Politicians promoting the same agenda form a party. Hence, the party structure follows directly from the politicians' decisions to promote agendas. We assume that the voters are uniformly distributed over the unit circle, with each voter's most preferred agenda coinciding with her location on the circle. Furthermore, voters are assumed to vote sincerely, i.e., support the party closest to their most preferred agendas. This assumption results in the vote share of each party to be proportional to its distance to the two adjacent parties. Next, the electoral system determines a mapping from the distribu-

\footnotetext{
${ }^{1}$ We solely focus on the pre-election process of strategic party formation. In particular, we ignore policy and welfare implications, and the impact of post-election coalition formation on actual power.

${ }^{2}$ According to Persson and Tabellini (2000, p.5), "It is hard to model the outcome of multiparty competition ...". As we will see, the transition to a circular agenda space may be a step forward.
} 
tion of votes to the distribution of "power". In the pluralitarian system, the parties with the highest vote share gain all power (winner takes all); in the proportional system, the power of each party equals its vote share. We assume that the politicians belonging to a party share equally in its power, and each politician is opportunistic (office-motivated), trying to maximize her individual power. Hence, in general, each politician prefers to become a member of a party with a high vote share but as few other members as possible.

We provide a full characterization of the sets of pure-strategy Nash equilibria in both the pluralitarian and proportional systems, and show that these sets are nonempty. Typically, both systems possess a rich set of Nash equilibria. ${ }^{3}$ Therefore, we define a notion of defection-proofness to refine the Nash equilibrium predictions. Defection-proof Nash equilibrium is similar in motivation to coalition-proof Nash equilibrium (Bernheim et al., 1987), but only allows for particular deviations, which we call defections. The defections include shifts in agenda, mergers of parties, and a set of politicians splitting from their original parties and forming a new party or joining an existing one. ${ }^{4}$ In the pluralitarian system, we show that Nash equilibria that generate strictly more than three parties are not defection-proof, whereas only multiple parties are supported as defection-proof Nash equilibrium under the proportional rule. Our defection-proof Nash equilibrium predictions are only partially consistent with Duverger's law - we predict either two or three parties under pluralitarian system - but they fully support Duverger's hypothesis and the Duvergerian comparative prediction.

In Section 2, we present the details of the model and the definition of defection-proofness. In Sections 3 and 4, we present, respectively, the equilibrium analysis for the pluralitarian and proportional systems. We conclude in Section 5 by summarizing our results. Proofs are collected in Section 6 .

\section{Model}

There is a finite set of politicians, $I$, with $|I| \geq 3 .{ }^{5}$ The set of agendas, $A$, is the circumference of a circle of unit length. An agenda is denoted by $a$. The politicians simultaneously choose to support agendas. We restrict attention to pure strategies. Therefore, $A$ is the set of strategies for each politician. A strategy profile is denoted by $s$. For any $J \subseteq I, s_{J}$ denotes the strategy profile $\left(s_{i}\right)_{i \in J}$ and $s_{-J}$ denotes the strategy profile $\left(s_{i}\right)_{i \in I \backslash J}$.

A strategy profile $s$ defines a partition $\mathcal{P}(s)$ of the set of politicians, where each $P \in \mathcal{P}(s)$ is such that for some agenda $a, s_{i}=a$ for all $i \in P$ and $s_{j} \neq a$ for all $j \notin P$. That is,

\footnotetext{
${ }^{3} \mathrm{~A}$ high multiplicity of (types of) equilibria is also found in a two-stage location-quantity game along the circle's circumference in Gupta et al. (2004).

${ }^{4}$ Duverger already reasoned that the field of parties is trimmed to just two by the forces of "fusion" and elimination (cf. Fey, 1997). Moreover, according to Kaminski (2006), "party politics revolves around the emergence of new parties [and] electoral splits and coalitions." Hence, the restriction to defections does not seem to be too restrictive.

${ }^{5}|X|$ is the cardinality of set $X$.
} 
every politicians who belongs to $P$ supports the same agenda $a$ in the profile $s$ and none of the politicians outside $P$ support the agenda $a$. We will refer to any $P \in \mathcal{P}(s)$ as a party. Hence, $\mathcal{P}(s)$ is the set of all parties formed in the strategy profile $s$. The agenda supported by a party $P \in \mathcal{P}(s)$ is the unique agenda supported by every politician who belongs to $P$. For any $P \in \mathcal{P}(s)$, let $R^{s}(P)$ be the first party that is supporting an agenda in the clockwise direction starting at the agenda supported by $P$. Similarly, let $L^{s}(P)$ be the first party that is supporting an agenda in the counterclockwise direction starting at the agenda supported by $P$. Any two parties $P, P^{\prime} \in \mathcal{P}(s)$ are adjacent if $P^{\prime} \in\left\{L^{s}(P), R^{s}(P)\right\}$.

Voters are uniformly distributed on $A$. Each voter's location on $A$ is her most-preferred agenda. Voters are assumed to vote sincerely for the party supporting the agenda closest to her most-preferred agenda; in case there are two such parties, she votes for each with equal probability - there cannot be more than two such parties since the set of agendas is a circle.

The weight of a party $P \in \mathcal{P}(s)$, denoted by $w_{P}(s)$, is the proportion of voters who vote for party $P$. We term the length of the arc between the agenda supported by $P$ and agenda supported by $L^{s}(P)$ as the left distance of party $P$ and denote it by $l^{s}(P)$. Similarly, the length of the arc between the agenda supported by $P$ and agenda supported by $R^{s}(P)$ will be called the right distance of party $P$ and denoted by $r^{s}(P)$. It is straightforward to show that $w_{P}(s)=\frac{l^{s}(P)+r^{s}(P)}{2}$ (see Figure 1). Note that $w_{P}(s) \geq 0$ for all $P \in \mathcal{P}(s)$ and $\sum_{P \in \mathcal{P}(s)} w_{P}(s)=1$. Then $w(s)=\left(w_{P}(s)\right)_{P \in \mathcal{P}(s)}$ is the distribution of weights under the strategy profile $s$.

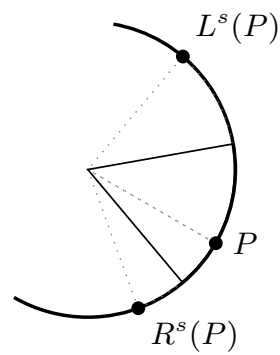

Figure 1: The dotted lines demarcate arcs that define the distance between adjacent parties. The thick lines demarcate arcs that define each party's voter base or weight. The weight of a party is the average of its left and right distances.

A rule $\rho$ defines for every strategy profile $s$, the power $\rho_{P}(w(s))$ of each party $P \in \mathcal{P}(s)$ as a function of the distribution of weights $w(s)$. We assume that the politicians belonging to a party share equally in its power. Furthermore, politicians receive utility equal to their individual power - such office-motivated politicians are standard in the literature. Hence, the utility of politician $i$ in strategy profile $s$ is $u_{i}(s)=\frac{\rho_{P}(w(s))}{|P|}$, where $i \in P \in \mathcal{P}(s)$.

For any rule $\rho$, a strategy profile $s$ is a Nash equilibrium if there do not exist $i \in I$ and $s_{i}^{\prime} \in A$ such that $u_{i}\left(s_{i}^{\prime}, s_{-i}\right)>u_{i}\left(s_{i}, s_{-i}\right)$. Thus, Nash equilibrium strategies are stable 
against unilateral deviations by a single politician. However, Nash equilibrium disregards the possibility of coordinated deviations or defections by a coalition of politicians.

Definition 1 (Defection). A defection from a strategy profile $s$ by a coalition $J \subseteq I$ is a strategy profile for coalition $J, s_{J}^{\prime} \in A^{|J|}$, such that $s_{j} \neq s_{j}^{\prime}=a$ for all $j \in J$, and $u_{j}\left(s_{J}^{\prime}, s_{-J}\right)>u_{j}\left(s_{J}, s_{-J}\right)$ for all $j \in J .^{6}$

Thus, a defection is a deviation from a strategy profile by a coalition of politicians that satisfies two requirements: first, all the members of the coalition deviate to the same agenda and second, all the members of the coalition must strictly improve their utilities after the deviation. The following are some examples of defections:

- Shift in a party's agenda: All the politicians in a party decide to shift the agenda supported by their party.

- Split in a party: A subset of politicians belonging to a party form a new party by supporting a different agenda.

- Merger of parties: All the politicians in two or more parties choose to support a new common agenda.

- A set of politicians split from their original parties and merge at a new or some previously supported agenda.

Such defections are quite common in politics and therefore, we allow for them in our model. However, unless binding agreements are possible among the defecting coalition, the defection must be self-enforcing or credible.

\section{Definition 2 (Credible Defection).}

(i) A credible defection from a strategy profile $s$ by a politician $j \in I$ is a $s_{j}^{\prime} \in A$ such that $s_{j}^{\prime}$ is a defection from $s$ by politician $j$.

(ii) A credible defection from a strategy profile $s$ by a coalition $J \subseteq I$ such that $|J|>1$ is a strategy profile for coalition $J, s_{J}^{\prime} \in A^{|J|}$, such that $s_{J}^{\prime}$ is a defection from $s$ by coalition $J$ and there does not exist any subcoalition $J^{\prime} \subset J$ with a credible defection from $\left(s_{J}^{\prime}, s_{-J}\right)$.

\footnotetext{
${ }^{6}$ It is standard to assume that while contemplating a deviation, a coalition considers the strategy of the complement as fixed. Moreover, one could imagine a stronger notion of defection that requires that in case the defecting coalition chooses an agenda that is already supported by another party, then the politicians in the latter party should also be better-off. The resulting notion of defection-proof Nash equilibrium can easily be shown to make precisely the same selection among Nash equilibria. However, this stronger definition of defection is not consistent with Nash equilibrium. After all, in Nash equilibrium, we consider defections by single politicians but do not care in case such a defection makes the party that this single politician joins worse off. Therefore, we should stick with the current weaker notion of defection.
} 
Thus, a credible defection by a coalition is such that no further credible defection is possible by any proper subcoalition.

Definition 3 (Defection-Proof Nash Equilibrium). A defection-proof Nash equilibrium is a strategy profile $s$ such that there is no credible defection from $s$ by any coalition $J \subseteq I$.

Defection-proof Nash equilibria are stable against credible defections by any coalition. Clearly, the set of defection-proof Nash equilibria is a subset of the set of Nash equilibria.

We restrict attention to two specific rules, plurality rule and proportional rule. Under the plurality rule, all parties with the maximum weight share power equally whereas any party with less than the maximum weight gets zero power. Formally, for any strategy profile $s$, the plurality rule defines the power of any $P \in \mathcal{P}(s)$ as

$$
P l_{P}(w(s)) \equiv \begin{cases}\frac{1}{\left\lceil\arg \max _{P^{\prime} \in \mathcal{P}(s)} w_{P^{\prime}}(s) \mid\right.} & \text { if } P \in \arg \max _{P^{\prime} \in \mathcal{P}(s)} w_{P^{\prime}}(s) \\ 0 & \text { otherwise. }\end{cases}
$$

Under the proportional rule, the power of a party equals its weight. Hence, for any strategy profile $s$, the proportional rule defines the power of any $P \in \mathcal{P}(s)$ as

$$
\operatorname{Pr}_{P}(w(s)) \equiv w_{P}(s)
$$

\section{Plurality Rule}

We begin with the characterization of the set of Nash equilibria under the plurality rule.

Theorem 1. Under plurality rule, a strategy profile $s$ is a Nash equilibrium if and only if the numbers of politicians in any two parties in $\mathcal{P}(s)$ differ by at most 1 , and exactly one of the following holds:

(i) $|\mathcal{P}(s)|=2$ and $\min \left\{l^{s}(P), r^{s}(P)\right\}>\frac{1}{3}$ for some $P \in \mathcal{P}(s)$.

(ii) $3 \leq|\mathcal{P}(s)| \leq \frac{|I|}{2}$ and all parties have equal weights.

(iii) $3 \leq|\mathcal{P}(s)| \leq 4,|\mathcal{P}(s)|>\frac{|I|}{2}$ and all parties are equidistant from each other.

(iv) $5 \leq|\mathcal{P}(s)| \leq 6,|\mathcal{P}(s)|>\frac{|I|}{2}$, all parties are equidistant from each other, and there does not exist any pair of singleton parties that are adjacent.

Thus, whether $s$ is a Nash equilibrium or not depends only on two factors: first, the respective distances between the agendas supported in $s$ - which determine the weights of the parties - and second, the numbers of politicians in the parties formed in $s$. Hence, if $s$ is a Nash equilibrium, then the strategy profile $s^{\prime}$ obtained by either shifting the agendas supported by all politicians by a fixed constant or permuting the identities of the politicians will also be a 
Nash equilibrium. This is obviously because of the particular specification of the utilities of the politicians.

An important property of Nash equilibrium under the plurality rule is that all parties formed in equilibrium have equal weight (Lemma 9). This is because only those parties with the maximum weight obtain positive power. Hence, if a party has less than the maximum weight, then a politician belonging to that party obtains zero utility but could obtain positive utility by deviating to an agenda supported by some party (more precisely, any party with the highest weight in the hypothetical situation in which the set of politicians is $I \backslash\{i\}$, where $i$ is the deviating politician, and these politicians choose agendas according to the strategy profile $\left.s_{-i}\right)$. The weight of a party is the average of its left and right distances. Thus, it follows that the sums of the left and right distances of all parties formed in equilibrium are equal. Since the right (left) distance of party $P^{k}$ is trivially equal to the left (right) distance of $R^{s}\left(P^{k}\right)$ $\left(L^{s}\left(P^{k}\right)\right)$, it follows that the left (right) distance of a party $P^{k}$ equals the right (left) distance of party $R^{s}\left(P^{k}\right)\left(L^{s}\left(P^{k}\right)\right)$. Therefore, if $\left\{P^{1}, \ldots, P^{n}\right\}$ is the set of parties that form in Nash equilibrium and, without loss of generality, $P^{k+1}=R^{s}\left(P^{k}\right)$ for all $k=1, \ldots, n-1$, then we obtain the following two sequences of equalities:

$$
\begin{aligned}
& l^{s}\left(P^{1}\right)=r^{s}\left(P^{2}\right)=l^{s}\left(P^{3}\right)=r^{s}\left(P^{4}\right)=\ldots \\
& l^{s}\left(P^{n}\right)=r^{s}\left(P^{1}\right)=l^{s}\left(P^{2}\right)=r^{s}\left(P^{3}\right)=\ldots
\end{aligned}
$$

In words, if we move along the circle in the clockwise direction, then every other arc defined by the set of agendas supported in equilibrium has the same length.

The property that all parties have equal weights in equilibrium, generates two possible configurations of parties in equilibrium:

(i) An odd number of parties form in equilibrium. Then all parties must be equidistant from each other. To see this, suppose $n=5$, i.e., five parties $P^{1}, \ldots, P^{5}$ form in equilibrium (see Figure 2(1)). Using (1), we obtain

$$
l^{s}\left(P^{1}\right)=r^{s}\left(P^{2}\right)=l^{s}\left(P^{3}\right)=r^{s}\left(P^{4}\right)=l^{s}\left(P^{5}\right)=r^{s}\left(P^{1}\right)=l^{s}\left(P^{2}\right)=r^{s}\left(P^{3}\right)=l^{s}\left(P^{4}\right)=r^{s}\left(P^{5}\right) .
$$

Since the parties are equidistant, the set of agendas supported in equilibrium $s$ can be graphically visualized as the vertices of a $n$-sided convex regular polygon (as shown in Figure 2(2)).

(ii) An even number of parties form in equilibrium. First, consider the case when more than two parties form. Then both equidistant and non-equidistant configurations are possible. Figure 3 shows these configurations with six parties. In general, we can graphically visualize the set of agendas supported in equilibrium as follows. Since the parties have equal weights, we have

$$
l^{s}\left(P^{2}\right)+r^{s}\left(P^{2}\right)=l^{s}\left(P^{4}\right)+r^{s}\left(P^{4}\right)=l^{s}\left(P^{6}\right)+r^{s}\left(P^{6}\right)=\ldots
$$




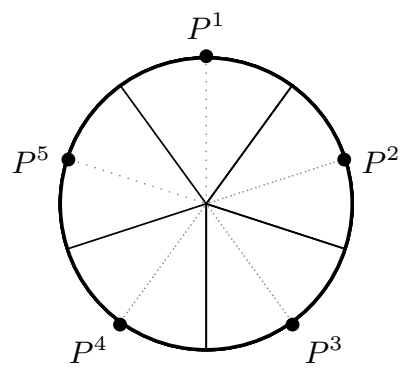

(1)

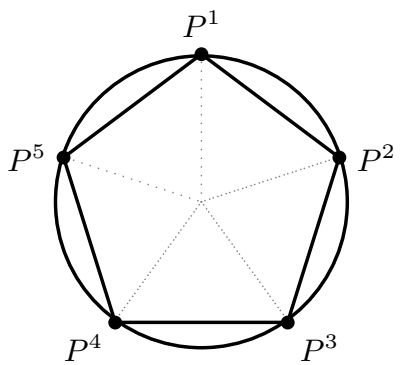

(2)

Figure 2: Odd number $(>1$ ) of parties under plurality rule: (1) All parties have equal weight and are equidistant. (2) The locations of the parties are the vertices of a convex regular polygon.

But $l^{s}\left(P^{2}\right)+r^{s}\left(P^{2}\right)$ is the distance between the agendas supported by parties $P^{1}$ and $P^{3} ; l^{s}\left(P^{4}\right)+r^{s}\left(P^{4}\right)$ is the distance between the agendas supported by parties $P^{3}$ and $P^{5}$ and so on. Hence, all odd-numbered parties $\left(P^{1}, P^{3}, \ldots, P^{n-3}, P^{n-1}\right)$ are equidistant from each other and thus, the agendas supported by these parties are vertices of an $\frac{n}{2}$-sided convex regular polygon (as shown in Figure 4(2)). Similarly, all even-numbered parties $\left(P^{2}, P^{4}, \ldots, P^{n-2}, P^{n}\right)$ are equidistant from each other and the agendas supported by these parties are also vertices of an $\frac{n}{2}$-sided convex regular polygon (as shown in Figure 4(2)). If in addition, all parties are equidistant from each other, then the agendas supported by all parties are vertices of a $n$-sided convex regular polygon (as shown in Figure 4(1)).

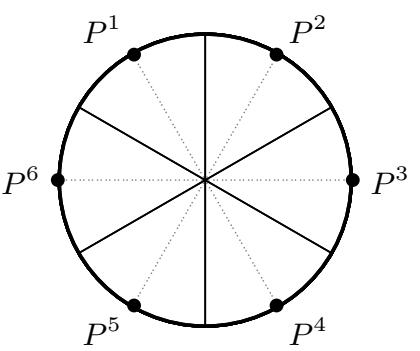

(1)

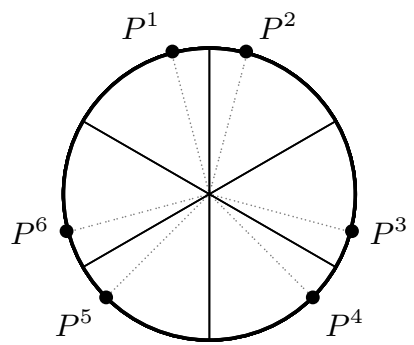

$(2)$

Figure 3: Even number $(>2)$ of parties under plurality rule: All parties have equal weight but both equidistant (shown in (1)) and non-equidistant (shown in (2)) configurations are possible. In (2), all even-numbered parties are equidistant from each other and all odd-numbered paries are equidistant from each other.

When only two parties form in equilibrium, each party has a weight of $\frac{1}{2}$. In this case, it must be that the minimum distance between the two parties is greater than $\frac{1}{3}$. Otherwise, a single politician from the party having the larger number of politicians - who obtains a utility of at most $\frac{1}{4}$ as she shares power of $\frac{1}{2}$ with at least one other politician - can deviate to the agenda in the middle of the longer arc between the agendas supported by the two parties. The left and right distances of this new singleton 


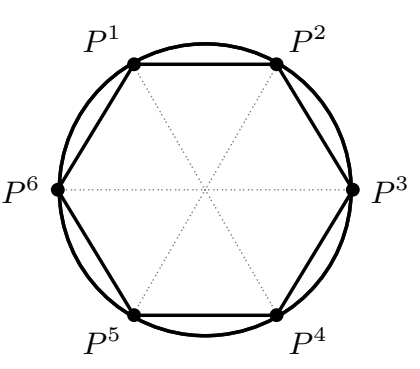

(1)

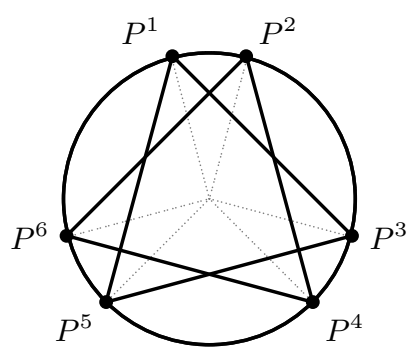

(2)

Figure 4: Even number $(>2)$ of parties under plurality rule: (1) When all parties are equidistant, their locations are the vertices of a convex regular polygon. (2) When parties are not equidistant, the locations of all even-numbered/odd-numbered parties are the vertices of a convex regular polygon.

party will be both at least $\frac{1}{3}$ and hence, it will have at least as much weight as the other two parties. Thus, the deviating politician will obtain a utility of at least $\frac{1}{3}$, which is a contradiction.

The utility of a politician is a function both of the weight of her party and the number of other politicians who belong to her party. Since all parties have the same weight in equilibrium, a politician in party $P$ obtains $\frac{1}{|P|}$ proportion of the weight. If there is another party $P^{\prime}$ such that $|P|>\left|P^{\prime}\right|+1$, then a politician from party $P$ could deviate to the agenda supported by $P^{\prime}$, increasing her utility to $\frac{1}{\left|P^{\prime}\right|+1}$ proportion of the weight. Therefore, the numbers of politicians in any two parties in $\mathcal{P}(s)$ differ by at most 1 in equilibrium.

It also follows from the theorem that the number of parties formed in equilibrium is bounded below by 2 and above by $\max \left\{\frac{|I|}{2}, 6\right\}$. Any strategy profile in which only a single party is formed is not an equilibrium since by deviating to any other agenda, any politician can form a singleton party with the weight of $\frac{1}{2}$ and hence, increase her utility from at most $\frac{1}{3}$ - since $|I| \geq 3$ - to $\frac{1}{2}$. On the other hand, suppose the number of parties formed in equilibrium is greater than both $\frac{|I|}{2}$ and 6. Figure 5(1) shows such a strategy profile when $|I|=17$ but nine parties form. Then at least one party, say $P^{2}$, is singleton and the utility of this politician is less than $\frac{1}{6}$ (see figure). Since the numbers of politicians in any two parties cannot differ by more than 1 , both $P^{1}=L^{s}\left(P^{2}\right)$ and $P^{3}=R^{s}\left(P^{2}\right)$ have at most two members. Without loss of generality, let $r^{s}\left(P^{2}\right) \leq l^{s}\left(P^{2}\right)$. If the single politician in $P^{2}$ were to deviate to the agenda supported by $P^{3}$ (as shown in Figure 5(2)), then the weight of party $P^{3} \cup P^{2}$ will increase by $\frac{l^{s}\left(P^{2}\right)}{2}$ and the weight of $P^{1}$ by $\frac{r^{s}\left(P^{2}\right)}{2}$, while the weights of all other parties will stay constant as the agendas supported by their respective adjacent parties stay fixed. Since we started with a situation of equal weights, the merged party $P^{3} \cup P^{2}$ will have the maximum weight and hence, through this deviation, the politician will obtain a utility of at least $\frac{1}{6}$ as she shares the power of at least $\frac{1}{2}$ with at most two other members, which is a contradiction.

The following corollary immediately follows from the above theorem. 


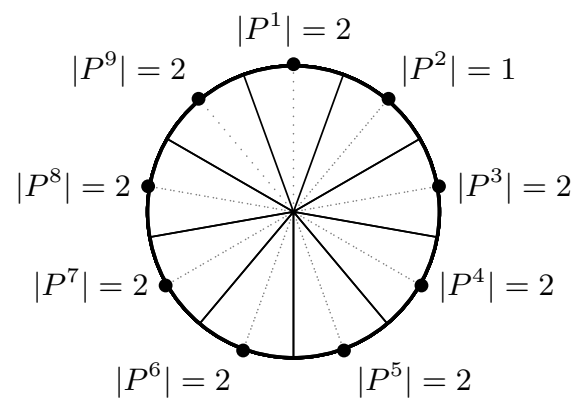

(1)

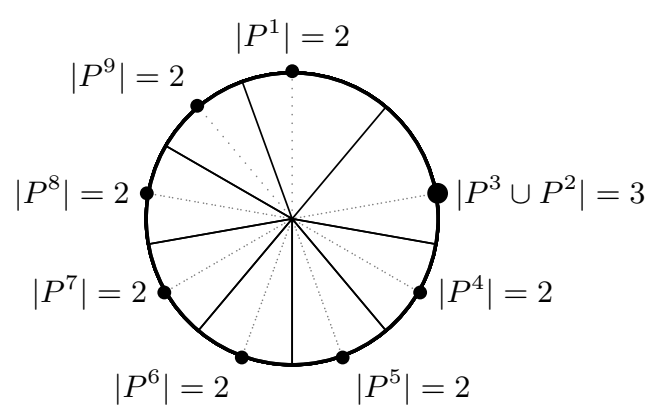

$(2)$

Figure 5: Number of parties is bounded above by $\max \left\{\frac{|I|}{2}, 6\right\}$ : Assume $|I|=17$. (1) A strategy profile in which 9 parties form. (2) A unilateral deviation by the politician in $P^{2}$ that increases her utility.

Corollary 2. For any $|I| \geq 3$, there exists a pure-strategy Nash equilibrium under plurality rule.

Indeed, the model under plurality rule has multiple Nash equilibria, with the number of political parties in equilibrium ranging from 2 to $\max \left\{\frac{|I|}{2}, 6\right\}$. Next, we refine our predictions using defection-proofness. The following theorem characterizes the set of defection-proof Nash equilibria.

Theorem 3. Under plurality rule, a strategy profile $s$ is a defection-proof Nash equilibrium if and only if the numbers of politicians in any two parties in $\mathcal{P}(s)$ differ by at most 1 and exactly one of the following holds:

(i) $|\mathcal{P}(s)|=2$ and $\min \left\{l^{s}(P), r^{s}(P)\right\}>\frac{1}{3}$ for some $P \in \mathcal{P}(s)$.

(ii) $|\mathcal{P}(s)|=3$ and all parties are equidistant from each other.

Thus, defection-proofness sharply refines the set of Nash equilibria: only those Nash equilibria in which either two or three parties form are defection-proof Nash equilibria. To see why Nash equilibria with at least four parties are not defection-proof, let's consider a Nash equilibrium $s$ in which $P^{1}, \ldots, P^{n}$ parties form, where $n \geq 4$, and all parties are equidistant, with the distance equal to $d$ (the proof takes care of all cases). Let $a$ be the agenda that is the midpoint of the agendas supported by $P^{2}$ and $P^{3}$ (as shown in Figure 6(1)). Now, if a coalition consisting of all politicians in $P^{2}$ and $P^{3}$ were to deviate to supporting a, ceteris paribus, then $n-1$ parties, viz. $\left\{P^{1}, P^{2} \cup P^{3}, P^{4}, \ldots, P^{n}\right\}$, will be formed in the resulting profile $s^{\prime}$ (as shown in Figure 6(2)). The weight of the party $P^{2} \cup P^{3}$ will be $\frac{3}{2} d$, while the weights of $P^{1}$ and $P^{4}$ will each be $\frac{5}{4} d$, and the weights of all other parties will remain unchanged. Since we started with a situation of equal weights, the merged party $P^{2} \cup P^{3}$ will be the unique party with the maximum weight and hence, each member of the deviating coalition will obtain a utility of $\frac{1}{\left|P^{2}\right|+\left|P^{3}\right|}$ compared to the utility of either $\frac{1}{n\left|P^{2}\right|}$ or $\frac{1}{n\left|P^{3}\right|}$ in profile $s$. Since $n \geq 4$ and the numbers of politicians in parties $P^{2}$ and $P^{3}$ do not differ from each other by more 
than 1 - since $s$ is a Nash equilibrium -, we have $n\left|P^{2}\right| \geq 4\left|P^{2}\right|>2\left|P^{2}\right|+1 \geq\left|P^{2}\right|+\left|P^{3}\right|$ and similarly, $n\left|P^{3}\right|>\left|P^{2}\right|+\left|P^{3}\right|$. Thus, each member of the deviating coalition will be strictly better-off after the deviation and hence, we have obtained a defection from $s$ by coalition $P^{2} \cup P^{3}$. This defection is in fact credible. Consider any subcoalition $J^{\prime} \subset P^{2} \cup P^{3}$. If starting from $s^{\prime}$, all members of $J^{\prime}$ were to deviate to an agenda like $a^{\prime}$, which lies on the arc between the agendas supported by $P^{1}$ and $P^{4}$ that does not contain $a$ (see Figure 6(2)), then at least as many agendas as in $s^{\prime}$ will be supported in the resulting profile $s^{\prime \prime}$. However, the weight of party $P^{2} \cup P^{3} \backslash J^{\prime}$ will not change while the weight of any other party will be at most $\frac{5}{4} d$. Hence, the subcoalition $J^{\prime}$ cannot improve its utility by this deviation. On the other hand, if starting from $s^{\prime}$, all members of $J^{\prime}$ were to deviate to an agenda like $a^{\prime \prime}$ or $a^{\prime \prime \prime}$, which lie between $a$ and the agenda supported by either $P^{1}$ or $P^{4}$ (see Figure 6(2)), then the weight of party $J^{\prime}$ will be $\frac{3}{4} d$, which is less than the weight of $P^{2} \cup P^{3} \backslash J^{\prime}$. Thus, $J^{\prime}$ cannot improve its utility by such a deviation. Hence, we conclude that the initial defection from $s$ is a credible defection.

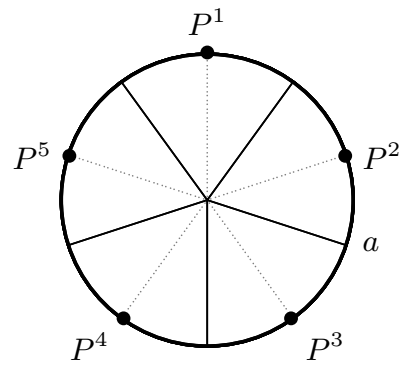

(1)

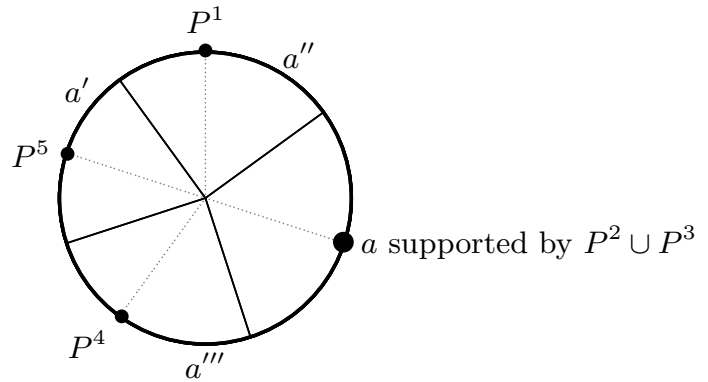

(2)

Figure 6: Nash equilibria with more than 3 parties are not defection-proof: (1) A Nash equilibrium with 5 parties. (2) A credible defection by $P^{2} \cup P^{3}$.

In contrast, all Nash equilibria in which either two or three parties form are defectionproof Nash equilibria. Let's consider a Nash equilibrium $s$ as shown in Figure 7(1) with three parties, $P^{1}, P^{2}$ and $P^{3}$ (the argument for two parties is similar). First, consider a defection in which all three parties merge, resulting in $s^{\prime}$ with a single agenda being supported. Since $s^{\prime}$ is not a Nash equilibrium, there exists a credible defection from $s^{\prime}$ by a single politician belonging to the initial defecting coalition. Thus, the initial defection cannot be credible. Second, consider a defection in which all politicians, except some in say $P^{3}$, merge, resulting in $s^{\prime}$ with two agendas being supported (as shown in Figure $7(2)$ ). Thus, instead of $\frac{1}{3\left|P^{1}\right|}$, a defecting politician belonging to $P^{1}$ obtains a utility of at most $\frac{1}{2\left|P^{1}\right|+2\left|P^{2}\right|}$ after the defection. But $2\left|P^{1}\right|+2\left|P^{2}\right| \geq 2\left|P^{1}\right|+\left|P^{2}\right|+1 \geq 3\left|P^{1}\right|$, where the last inequality follows from the fact that the numbers of politicians in parties $P^{1}$ and $P^{2}$ do not differ from each other by more than 1 . Thus, any politician belonging to $P^{1}$ will not improve her utility through this defection, a contradiction. Third, any defection that results in a $s^{\prime}$ in which three agendas 
are supported must be such that at least two agendas supported in $s$, say those of $P^{2}$ and $P^{3}$, are also supported in $s^{\prime}$. That is, some politicians belonging to $P^{2}$ and $P^{3}$ are not members of the defecting coalition. If the party formed supports an agenda which is different than the agenda supported by $P_{1}$ in $s$, then it has a weight of $\frac{1}{3}$ (Figure $7(3)$ ) or $\frac{1}{6}$ (Figure $7(4)$ ) depending on the arc on which the agenda is placed. In both cases, there is at least one party with a weight of strictly more than $\frac{1}{3}$. Therefore, the party formed has zero power and so the defection is not beneficial. If the party formed supports the agenda supported by $P_{1}$ in $s$, then all three agendas supported in $s$ are also supported in $s^{\prime}$. But such a defection even by a single politician is not beneficial since $s$ is a Nash equilibrium. Finally, any defection that results in a $s^{\prime}$ in which four agendas are supported must be such that all three agendas supported in $s$ are also supported in $s^{\prime}$ (note that there does not exist a defection that results in five or more supported agendas). But this cannot be beneficial for the same reasoning above. Thus there is no credible defection from $s$ by any coalition.

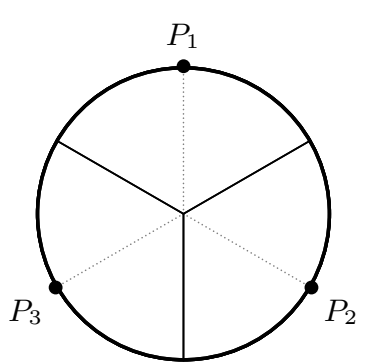

(1)

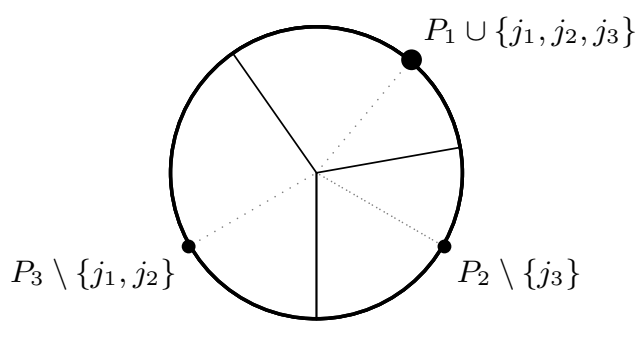

(3)

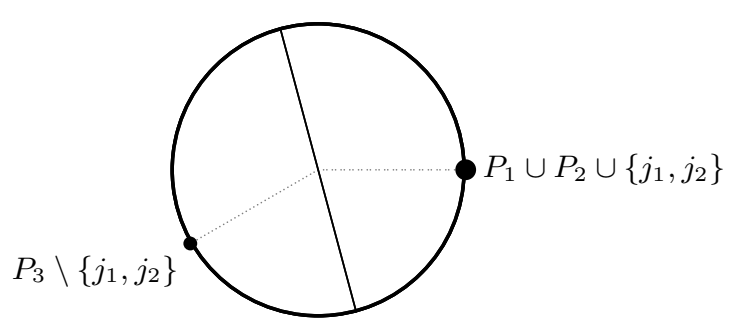

$(2)$

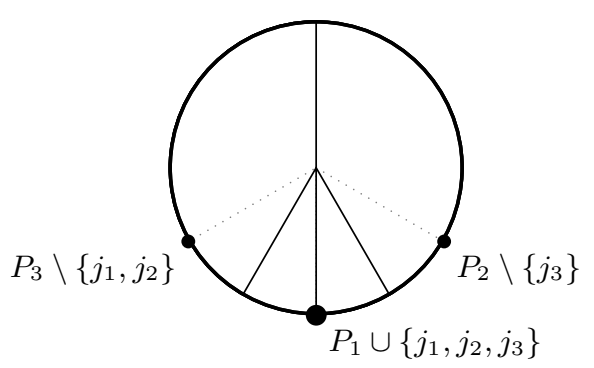

(4)

Figure 7: Nash equilibria with 3 parties are defection-proof: (1) A Nash equilibrium with 3 parties. (2) There do not exist defections that result in only two supported agendas. (3) and (4) show that there do not exist defections that result in three supported agendas.

As a corollary, we easily obtain the following result:

Corollary 4. For any $|I| \geq 3$, there exists a defection-proof Nash equilibrium under plurality rule. 


\section{Proportional Rule}

In this section, we study the formation of political parties under the proportional rule. Like in the plurality rule, the vote share or weight of any party is equal to the average of its left and right distances. However, in contrast, now every party has positive power equal to its weight. As the next theorem shows, this substantially alters the configurations of political parties that form in Nash equilibria.

Theorem 5. Under proportional rule, $s$ is a Nash equilibrium if and only if for any party $P \in \mathcal{P}(s)$ either

(i) $|P|=2$ and $l^{s}(P)=r^{s}(P)=\max _{P^{\prime} \in \mathcal{P}(s)}\left\{l^{s}\left(P^{\prime}\right), r^{s}\left(P^{\prime}\right)\right\}$ or

(ii) $|P|=1$ and $l^{s}(P)+r^{s}(P) \geq \max _{P^{\prime} \in \mathcal{P}(s)}\left\{l^{s}\left(P^{\prime}\right), r^{s}\left(P^{\prime}\right)\right\}$.

According to the theorem, all parties have at most two politicians in any Nash equilibrium. To see this, suppose a party $P$ has at least three politicians in a Nash equilibrium $s$ (as shown in Figure $8(1))$. The weight of this party equals $\frac{l^{s}(P)+r^{s}(P)}{2}$. Since $P$ has at least three politicians, any politician in $P$ obtains a utility of at most $\frac{l^{s}(P)+r^{s}(P)}{6}$. If any politician in $P$ were to unilaterally deviate to an agenda on the arc corresponding to $\max \left\{l^{s}(P), r^{s}(P)\right\}$, then she would form a new singleton party with weight $\frac{\max \left\{l^{s}(P), r^{s}(P)\right\}}{2}$ (as shown in Figure $8(2)$ ). Clearly, $\frac{l^{s}(P)+r^{s}(P)}{6}<\frac{\max \left\{l^{s}(P), r^{s}(P)\right\}}{2}$. Hence, a strategy profile in which there exists a party with at least three politicians cannot be a Nash equilibrium.

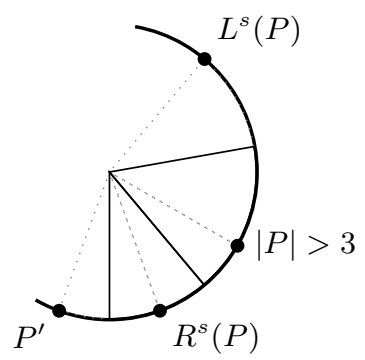

(1)

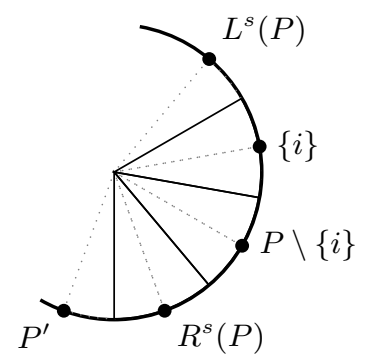

(2)

Figure 8: All parties in Nash equilibrium have at most 2 members: (1) A strategy profile with $|P|>3$.

(2) A unilateral deviation by some $i \in P$ that increases $i$ 's utility.

Moreover, in any Nash equilibrium, any party with two politicians must be equidistant from the parties that are adjacent to it, with the distance equal to $d^{*}=\max _{P^{\prime} \in \mathcal{P}(s)}\left\{l^{s}\left(P^{\prime}\right)\right.$, $\left.r^{s}\left(P^{\prime}\right)\right\}$, i.e., the maximum distance between any two adjacent parties. If not, then any politician in such a party $P$ shares a weight of $\frac{l^{s}(P)+r^{s}(P)}{2}<d^{*}$ with the other politician in $P$ and hence, obtains $\frac{l^{s}(P)+r^{s}(P)}{4}<\frac{d^{*}}{2}$. If this politician were to unilaterally deviate to an agenda on any arc corresponding to $d^{*}$, she would increase her utility to $\frac{d^{*}}{2}$, which is a contradiction to Nash equilibrium. 
Finally, the second condition in the theorem says that any singleton party in any Nash equilibrium must obtain a weight of at least $\frac{d^{*}}{2}$. The politician in a singleton party obtains a utility equal to the her party's weight. Therefore, if the second condition were violated, this politician could unilaterally deviate to an agenda on any arc corresponding to $d^{*}$ and increase her utility to $\frac{d^{*}}{2}$.

An upper bound of two on the membership of any party in Nash equilibrium implies that a large number of parties form under the proportional rule when the number of politicians is not too small. In particular, the number of parties in any Nash equilibrium must be at least $\frac{|I|}{2}$, if $|I|$ is even, and at least $\frac{|I|+1}{2}$, if $|I|$ is odd. Furthermore, every integer number of political parties, starting from $\frac{|I|}{2}$ or $\frac{|I|+1}{2}$ up to $|I|$, can be found in some Nash equilibrium. To see this, pick any integer $n$ in the interval $\left[\frac{|I|}{2},|I|\right]$ and construct a $n$-sided regular convex polygon in the unit circle. The agendas corresponding to the vertices of this polygon are equidistant by construction. Therefore, any distribution of the politicians over these agendas such that each agenda has at least one and at most two politicians satisfies the conditions in the theorem and hence, it is a Nash equilibrium (for example, see Figure 9(1)). However, it is not necessary that the agendas supported in Nash equilibrium are equidistant. For instance, consider the case when $|I|=10$. Then the following strategy profile with nine parties is a Nash equilibrium: there is a single party with two politicians and at a distance of $\frac{2}{11}$ from each of its adjacent parties, and the rest of the eight singleton parties are at a distance of $\frac{1}{11}$ from each other (see Figure 9(2)).

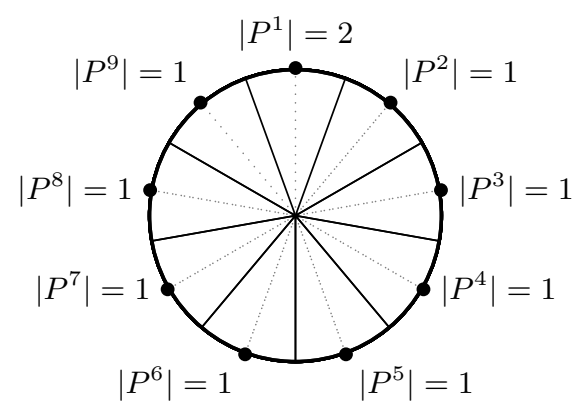

(1)

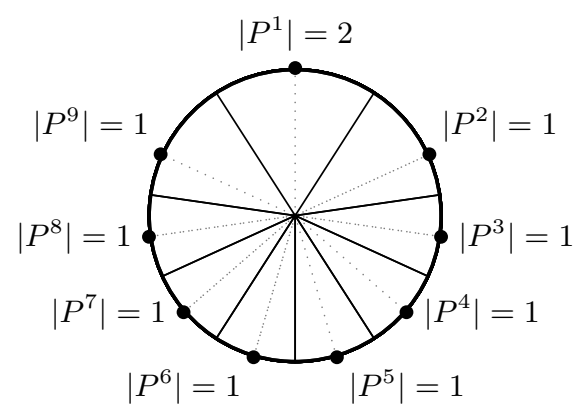

(2)

Figure 9: $|I|=10$. (1) Nash equilibrium with 9 equidistant parties. (2) Nash equilibrium with 9 parties that are not equidistant.

The following corollary follows from the theorem (see the discussion in the previous paragraph).

Corollary 6. For any $|I| \geq 3$, there exists a pure-strategy Nash equilibrium under proportional rule.

We also have multiple Nash equilibria under the proportional rule, with the number of political parties that can form in Nash equilibrium ranging from $\frac{|I|}{2}$ or $\frac{|I|+1}{2}$ up to $|I|$. Like for the 
plurality rule, we now use the notion of defection-proofness with the aim of refining the set of Nash equilibria. However, in contrast to the plurality rule, defection-proofness has no bite under the proportional rule.

Theorem 7. Under proportional rule, $s$ is a defection-proof Nash equilibrium if and only if it is a Nash equilibrium.

As we argue in the proof, any defection $s_{J}^{\prime}$ from a Nash equilibrium $s$ by a coalition $J$ to an agenda $a$ such that at least three politicians support $a$ in the resulting strategy profile $\left(s_{J}^{\prime}, s_{-J}\right)$ cannot be credible. This is because of the same reason why any strategy profile in which there exists a party with at least three politicians is not a Nash equilibrium: any politician in the party supporting $a$, and hence in $J$, can unilaterally deviate to improve her utility, which is a credible defection from $\left(s_{J}^{\prime}, s_{-J}\right)$.

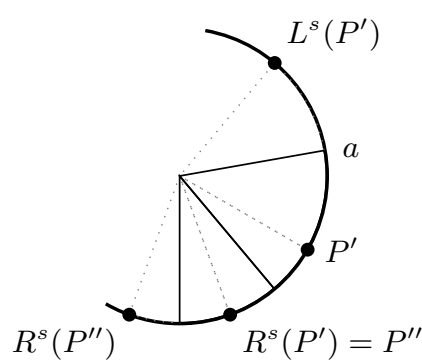

(1)

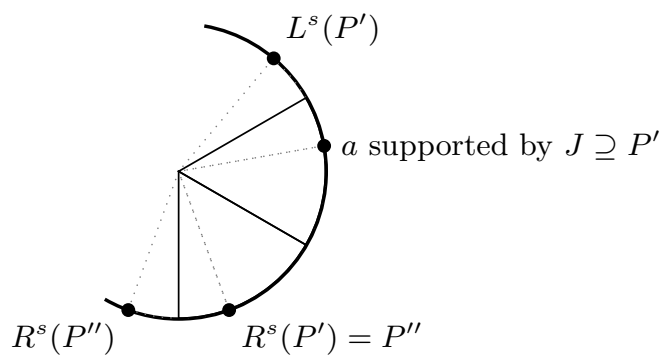

(3)

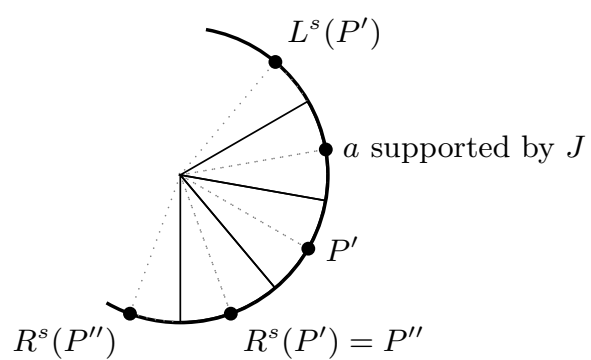

$(2)$

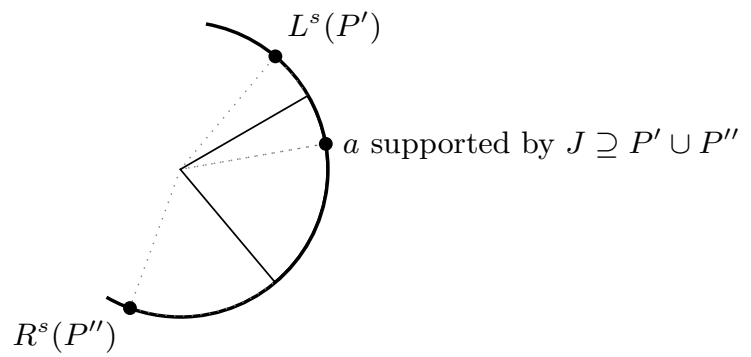

(4)

Figure 10: (1) Nash equilibrium $s$. There does not exist a defection by $J$ to agenda $a$ such that: (2) The agendas supported by $P^{\prime}$ and $L^{s}\left(P^{\prime}\right)$ in $s$ are also supported in $s^{\prime}$. (3) The agendas supported by $L^{s}\left(P^{\prime}\right)$ and $R^{s}\left(P^{\prime}\right)$ in $s$ are also supported in $s^{\prime}$ but the agenda supported by $P^{\prime}$ in $s$ is not supported in $s^{\prime}$. (4) The agenda supported by $L^{s}\left(P^{\prime}\right)$ in $s$ is also supported in $s^{\prime}$ but the agendas supported by $P^{\prime}$ and $R^{s}\left(P^{\prime}\right)$ in $s$ are not supported in $s^{\prime}$.

Thus, if there exists a credible defection from $s$, it must involve a coalition $J$ with exactly two politicians - a defection by a single politician does not exist since $s$ is a Nash equilibrium. Moreover, the credible defection must be to an agenda $a$ that is not supported by any party in $s$, i.e., a must lie between the agendas supported by two adjacent parties in $s$, say $P^{\prime}$ and $L^{s}\left(P^{\prime}\right)$ (as shown in Figure 10(1)). We argue that there does not exist any such defection from $s$. To see this, first suppose that both the agendas supported by $P^{\prime}$ and $L^{s}\left(P^{\prime}\right)$ in $s$ 
are also supported in $s^{\prime}=\left(s_{J}^{\prime}, s_{-J}\right)$ (as shown in Figure 10(2)). Then in the strategy profile $s^{\prime}$, the utility of each politician in $J$ equals $\frac{l^{s}\left(P^{\prime}\right)}{4}$. If this were a defection from $s$, increasing the utility of both politicians in $J$ over their utilities in the strategy profile $s$, then $s$ could not have been a Nash equilibrium. This is because when the strategy profile is $s$, any single politician in $J$ could unilaterally deviate to $a$ and obtain the utility $\frac{l^{s}\left(P^{\prime}\right)}{2}$ as she now forms a singleton party supporting an agenda between the agendas supported by $P^{\prime}$ and $L^{s}\left(P^{\prime}\right)$ in $s$, which remain supported after her deviation. Next, suppose that only the agenda supported by $L^{s}\left(P^{\prime}\right)$ in $s$ is supported in $s^{\prime}$. Then all the politicians in $P^{\prime}$ must be part of the defecting coalition $J$. If the agenda supported by $R^{s}\left(P^{\prime}\right)$ in $s$ is also supported in $s^{\prime}$ (as shown in Figure 10(3)), then the utility of any politician in $P^{\prime}$ in $s^{\prime}$ cannot be greater than her utility in $s$ since the weight of her party is the same in both profiles. On the other hand, if the agenda supported by $R^{s}\left(P^{\prime}\right)$ in $s$ is not supported in $s^{\prime}$ (as shown in Figure 10(4)), then all the politicians in $R^{s}\left(P^{\prime}\right)$ must also be part of the defecting coalition. But if two different parties in $s$ are part of the defecting coalition and the size of the defecting coalition is equal to two, then each of the defecting parties must be singleton. Moreover, letting $P^{\prime \prime}=R^{s}\left(P^{\prime}\right)$, it must be that none of the politicians in $R^{s}\left(P^{\prime \prime}\right)$ are part of $J$. Therefore, each politician in $J$ obtains $\frac{l^{s}\left(P^{\prime}\right)+r^{s}\left(P^{\prime}\right)+r^{s}\left(P^{\prime \prime}\right)}{4}$ after the defection. This is no more than $\frac{l^{s}\left(P^{\prime}\right)+r^{s}\left(P^{\prime}\right)}{2}$, the utility of the politician in the singleton party $P^{\prime}$ in $s$, because $l^{s}\left(P^{\prime}\right)+r^{s}\left(P^{\prime}\right)$ is at least equal to the maximum distance between any two adjacent parties in $s$ (second condition in Theorem $5)$. The argument in the other two cases - when only the agenda supported by $P^{\prime}$ in $s$ is supported in $s^{\prime}$ and when neither the agenda supported by $P^{\prime}$ nor by $L^{s}\left(P^{\prime}\right)$ in $s$ is supported in $s^{\prime}-$ is similar.

Since there exists a pure-strategy Nash equilibrium under the proportional rule, we have the following corollary:

Corollary 8. For any $|I| \geq 3$, there exists a defection-proof Nash equilibrium under proportional rule.

\section{Summary}

Our aim in this paper was to study whether the predictions of Duverger (1954) have game theoretic foundations in a spatial model. Unfortunately, the standard model with a linear set of agendas does not provide satisfactory answers to this question; the set of pure-strategy Nash equilibria is empty under the proportional rule whereas it is singleton under the plurality rule for refinements that allow explicit coordination on party-level. Hence, we instead used the set of agendas equal to the unit circle. As we have shown, this departure generates significantly different results; we now have multiple pure-strategy Nash equilibria under both rules. We used the notion of defection-proof Nash equilibrium to refine our predictions. Under 
the plurality rule, either two or three parties form in any defection-proof Nash equilibrium. This result is only partially consistent with Duverger's law since there exists defection-proof Nash equilibria with three parties. On the other hand, under the proportional rule, multiple parties form in any defection-proof Nash equilibrium. Thus, Duverger's hypothesis and the Duvergian comparative prediction are supported by our results.

\section{Proofs}

\subsection{Plurality Rule}

Proof of Theorem 1: We prove the theorem through a series of lemmas.

Lemma 9. If $s$ is a Nash equilibrium with $|\mathcal{P}(s)| \geq 2$, then all parties in $\mathcal{P}(s)$ have equal weights.

Proof. Suppose $s$ is a Nash equilibrium with $|\mathcal{P}(s)| \geq 2$ but there exists a $P \in \mathcal{P}(s)$ such that $w_{P}(s)<\max _{P^{\prime} \in \mathcal{P}(s)} w_{P^{\prime}}(s)$. Hence, $P l_{P}(w(s))=0$ and $u_{i}(s)=0$ for all $i \in P$. Pick any politician $i \in P$ and party $\hat{P} \in \arg \max _{P^{\prime} \in \mathcal{P}(s)} w_{P^{\prime}}(s)$. Consider the strategy profile $\left(s_{i}^{\prime}, s_{-i}\right)$ such that $s_{i}^{\prime}=\hat{a}$, where $\hat{a}$ is the agenda supported by $\hat{P}$ in $s$. Note that $\hat{P} \cup\{i\} \in \mathcal{P}\left(s_{i}^{\prime}, s_{-i}\right)$. If $\hat{P} \cup\{i\}=\arg \max _{P^{\prime} \in \mathcal{P}\left(s_{i}^{\prime}, s_{-i}\right)} w_{P^{\prime}}\left(s_{i}^{\prime}, s_{-i}\right)$, then $u_{i}\left(s_{i}^{\prime}, s_{-i}\right)>0$, a contradiction. If not, then pick any $\hat{P}^{\prime} \in \arg \max _{P^{\prime} \in \mathcal{P}\left(s_{i}^{\prime}, s_{-i}\right)} w_{P^{\prime}}\left(s_{i}^{\prime}, s_{-i}\right)$. Let $\hat{a}^{\prime}$ be the agenda supported by $\hat{P}^{\prime}$ in $\left(s_{i}^{\prime}, s_{-i}\right)$. Consider the strategy $\left(s_{i}^{\prime \prime}, s_{-i}\right)$ such that $s_{i}^{\prime \prime}=\hat{a}^{\prime}$. The sets of agendas supported by the parties are the same in $\left(s_{i}^{\prime}, s_{-i}\right)$ and $\left(s_{i}^{\prime \prime}, s_{-i}\right)$. Hence, $\hat{P}^{\prime} \cup\{i\} \in \arg \max _{P^{\prime} \in \mathcal{P}\left(s_{i}^{\prime \prime}, s_{-i}\right)} w_{P^{\prime}}\left(s_{i}^{\prime \prime}, s_{-i}\right)$. Therefore, $u_{i}\left(s_{i}^{\prime \prime}, s_{-i}\right)>0$, a contradiction.

Lemma 10. If $s$ is a Nash equilibrium with $|\mathcal{P}(s)| \geq 2$, then for any two adjacent parties $P$ and $P^{\prime}$ in $\mathcal{P}(s)$, we have $l^{s}(P)=r^{s}\left(P^{\prime}\right)$ and $r^{s}(P)=l^{s}\left(P^{\prime}\right)$. Furthermore, if $|\mathcal{P}(s)|$ is odd, then all parties are equidistant from each other.

Proof. Let $P$ and $P^{\prime}$ be two adjacent parties in $\mathcal{P}(s)$. Without loss of generality, let $P^{\prime}=$ $L^{s}(P)$. Hence, $l^{s}(P)=r^{s}\left(P^{\prime}\right)$. By Lemma $9, P$ and $P^{\prime}$ have equal weights. So $r^{s}(P)=l^{s}\left(P^{\prime}\right)$.

Let $P^{1}=P$ and $P^{k+1}=R^{s}\left(P^{k}\right)$ for $k=1, \ldots,|\mathcal{P}(s)|-1$. Note that $P^{|\mathcal{P}(s)|}=P^{\prime}$. If $|\mathcal{P}(s)|$ is odd, then we have $r^{s}\left(P^{1}\right)=l^{s}\left(P^{2}\right)=r^{s}\left(P^{3}\right)=\ldots=r^{s}\left(P^{|\mathcal{P}(s)|}\right), r^{s}\left(P^{|\mathcal{P}(s)|}\right)=l^{s}\left(P^{1}\right)$ and $l^{s}\left(P^{1}\right)=r^{s}\left(P^{2}\right)=l^{s}\left(P^{3}\right)=\ldots=l^{s}\left(P^{|\mathcal{P}(s)|}\right)$. Therefore, all parties are equidistant from each other.

Lemma 11. If $s$ is a Nash equilibrium with $|\mathcal{P}(s)| \geq 2$, then $\max _{P, P^{\prime} \in \mathcal{P}(s)}|P|-\left|P^{\prime}\right| \leq 1$.

Proof. Pick any $P, P^{\prime} \in \mathcal{P}(s)$. Without loss of generality, let $|P|>\left|P^{\prime}\right|+1$. Consider a politician $i \in P$. We have $u_{i}(s)=\frac{w_{P}(s)}{|P|}$. Let $s_{i}^{\prime}=a^{\prime}$, where $a^{\prime}$ is the agenda supported by party $P^{\prime}$ in $s$. Since the sets of agendas supported in $\left(s_{i}^{\prime}, s_{-i}\right)$ and $s$ are the same, all parties formed in $\left(s_{i}^{\prime}, s_{-i}\right)$ have equal weights ( $s$ is a Nash equilibrium and Lemma 9$)$. Furthermore, the weight 
of party $P^{\prime} \cup\{i\}$ in the strategy profile $\left(s_{i}^{\prime}, s_{-i}\right)$ is equal to $w_{P^{\prime}}(s)$. Hence, $u_{i}\left(s_{i}^{\prime}, s_{-i}\right)=\frac{w_{P^{\prime}}(s)}{\left|P^{\prime}\right|+1}$. But $w_{P}(s)=w_{P^{\prime}}(s)$, by Lemma 9 . Therefore, $u_{i}\left(s_{i}^{\prime}, s_{-i}\right)>u_{i}(s)$, a contradiction.

Lemma 12. A strategy profile $s$ such that $|\mathcal{P}(s)|=2$ is a Nash equilibrium if and only if $\min \left\{l^{s}(P), r^{s}(P)\right\}>\frac{1}{3}$ for any $P \in \mathcal{P}(s)$ and $\max _{P, P^{\prime} \in \mathcal{P}(s)}|P|-\left|P^{\prime}\right| \leq 1$.

Proof. Let $s$ be a Nash equilibrium such that $|\mathcal{P}(s)|=2$. Then $\max _{P, P^{\prime} \in \mathcal{P}(s)}|P|-\left|P^{\prime}\right| \leq 1$ follows from Lemma 11.

Let $\mathcal{P}(s)=\left\{P, P^{\prime}\right\}$. Since $|I| \geq 3$, at least one of the parties is not singleton. Without loss of generality, let $|P|>1$. Pick an $i \in P$. Since $w_{P}(s)=w_{P^{\prime}}(s)=\frac{1}{2}$, we have $u_{i}(s) \leq \frac{1}{4}$.

Let $d=\min \left\{l^{s}(P), r^{s}(P)\right\}$. We call the arc between the agendas supported by parties $P$ and $P^{\prime}$ in $s$ with length $d$ as $\operatorname{arc} d$, and the other arc as arc $1-d$ (in case $d=\frac{1}{2}$, then call any one of the two arcs defined by the agendas supported by $P$ and $P^{\prime}$ in $s$ as arc $d$ and the other as arc $1-d)$.

Suppose $d \leq \frac{1}{3}$. Let politician $i$ deviate to $s_{i}^{\prime}$, which is the midpoint of arc $1-d$. In strategy profile $\left(s_{i}^{\prime}, s_{-i}\right)$, there are three parties $\{i\}, P \backslash\{i\}$ and $P^{\prime}$. Furthermore, $w_{\{i\}}\left(s_{i}^{\prime}, s_{-i}\right)=\frac{1-d}{2} \geq$ $\frac{1}{3}, w_{P \backslash\{i\}}\left(s_{i}^{\prime}, s_{-i}\right)=w_{P^{\prime}}\left(s_{i}^{\prime}, s_{-i}\right)=\frac{1+d}{4} \leq \frac{1}{3}$. Hence, $u_{i}\left(s_{i}^{\prime}, s_{-i}\right) \geq \frac{1}{3}$, a contradiction.

To prove the other implication, suppose $s$ is a strategy profile with $\mathcal{P}(s)=\left\{P, P^{\prime}\right\}, d>\frac{1}{3}$ and $\max _{P, P^{\prime} \in \mathcal{P}(s)}|P|-\left|P^{\prime}\right| \leq 1$. Pick any $i \in P$. We have $u_{i}(s)=\frac{1}{2|P|}$. Consider any deviation $s_{i}^{\prime}$ by politician $i$. Now, two cases are possible:

(i) $|P|>1$ : Suppose $s_{i}^{\prime}$ is an unsupported agenda on arc $d$. Then three parties $\{i\}, P \backslash\{i\}$ and $P^{\prime}$ form in $\left(s_{i}^{\prime}, s_{-i}\right)$. Moreover, $w_{\{i\}}\left(s_{i}^{\prime}, s_{-i}\right)=\frac{d}{2}$ but $w_{P \backslash\{i\}}\left(s_{i}^{\prime}, s_{-i}\right)>\frac{1}{2}-\frac{d}{2} \geq \frac{d}{2}$ since $d \leq \frac{1}{2}$. Hence, $u_{i}\left(s_{i}^{\prime}, s_{-i}\right)=0$. Hence, $i$ has no incentive to deviate from $s_{i}$ to $s_{i}^{\prime}$. Next, suppose $s_{i}^{\prime}$ is an unsupported agenda on arc $1-d$. Again, three parties $\{i\}$, $P \backslash\{i\}$ and $P^{\prime}$ form in $\left(s_{i}^{\prime}, s_{-i}\right)$. Moreover, $w_{\{i\}}\left(s_{i}^{\prime}, s_{-i}\right)=\frac{1-d}{2}$ but either $P^{\prime}$ or $P \backslash\{i\}$ has a weight of at least $\frac{1+d}{4}>\frac{1-d}{2}$ since $d>\frac{1}{3}$. Hence, $u_{i}\left(s_{i}^{\prime}, s_{-i}\right)=0$ and $i$ has no incentive to deviate from $s_{i}$ to $s_{i}^{\prime}$. Finally, if $s_{i}^{\prime}$ is the agenda supported by party $P^{\prime}$ in $s$, then $u_{i}\left(s_{i}^{\prime}, s_{-i}\right)=\frac{1}{2\left(\left|P^{\prime}\right|+1\right)} \leq \frac{1}{2|P|}$ since $|P|-\left|P^{\prime}\right| \leq 1$. So $i$ has no incentive to make this deviation.

(ii) $|P|=1$ : As long as $s_{i}^{\prime}$ is not the agenda supported by $P^{\prime}, u_{i}\left(s_{i}^{\prime}, s_{-i}\right)=\frac{1}{2}$. If $s_{i}^{\prime}$ is the agenda supported by $P^{\prime}$, then $u_{i}\left(s_{i}^{\prime}, s_{-i}\right)=\frac{1}{\left|P^{\prime}\right|+1} \leq \frac{1}{3}$. So $i$ has no incentive to deviate.

A similar argument can be made for any politician in party $P^{\prime}$. Hence, $s$ is a Nash equilibrium.

Lemma 13. A strategy profile $s$ such that $|\mathcal{P}(s)| \geq 3$ and $|I| \geq 2|\mathcal{P}(s)|$ is a Nash equilibrium if and only if all parties in $\mathcal{P}(s)$ have equal weights and $\max _{P, P^{\prime} \in \mathcal{P}(s)}|P|-\left|P^{\prime}\right| \leq 1$. 
Proof. Suppose strategy profile $s$ is such that all parties have equal weights and $\max _{P, P^{\prime} \in \mathcal{P}(s)}$ $|P|-\left|P^{\prime}\right| \leq 1$. Pick any $P \in \mathcal{P}(s)$ and $i \in P$. Since $w_{P}(s)=\frac{1}{|\mathcal{P}(s)|}$, we have $u_{i}(s)=\frac{1}{|\mathcal{P}(s)||P|}$. Furthermore, since $|I| \geq 2|\mathcal{P}(s)|$, we must have $\left|P^{\prime}\right| \geq 2$ for all $P^{\prime} \in \mathcal{P}(s)$. Consider any deviation $s_{i}^{\prime}$ by politician $i$. If $s_{i}^{\prime}$ is an agenda supported by some $P^{\prime} \in \mathcal{P}(s)$, then the sets of agendas supported by the parties are the same in $s$ and $\left(s_{i}^{\prime}, s_{-i}\right)$. Hence, all parties formed in $\left(s_{i}^{\prime}, s_{-i}\right)$ have equal weights and $w_{P^{\prime} \cup\{i\}}\left(s_{i}^{\prime}, s_{-i}\right)=w_{P^{\prime}}(s)$. Therefore, $u_{i}\left(s_{i}^{\prime}, s_{-i}\right)=$ $\frac{1}{|\mathcal{P}(s)|\left(\left|P^{\prime}\right|+1\right)} \leq \frac{1}{|\mathcal{P}(s)||P|}$ since $|P| \leq\left|P^{\prime}\right|+1$. If $s_{i}^{\prime}$ is an agenda that is not supported in strategy $s$, then there exists a $P^{\prime} \in \mathcal{P}(s)$ such that $s_{i}^{\prime}$ is between the agendas supported by $P^{\prime}$ and $L^{s}\left(P^{\prime}\right)$ in $s$. Hence, $w_{\{i\}}\left(s_{i}^{\prime}, s_{-i}\right)=\frac{l^{s}\left(P^{\prime}\right)}{2}$. But the weight of party $R^{\left(s_{i}^{\prime}, s_{i}\right)}\left(P^{\prime}\right)$ in $\left(s_{i}^{\prime}, s_{-i}\right)$ equals $\frac{l^{s}\left(P^{\prime}\right)+r^{s}\left(P^{\prime}\right)}{2}$ (using the fact that there are at least three parties in $s$ and all these parties have equal weights). Hence, $u_{i}\left(s_{i}^{\prime}, s_{-i}\right)=0$ and therefore, there is no incentive for her to deviate. Lemmas 9 and 11 prove the other implication.

Lemma 14. There does not exist a Nash equilibrium s such that either (i) $|\mathcal{P}(s)|=1$ or (ii) $|\mathcal{P}(s)|>6$ and $|I|<2|\mathcal{P}(s)|$.

Proof. Suppose $s$ is such a Nash equilibrium. If $|\mathcal{P}(s)|=1$, then any politician $i$ can deviate to any $s_{i}^{\prime}$ and obtain $u_{i}\left(s_{i}^{\prime}, s_{-i}\right)=\frac{1}{2}>\frac{1}{|I|}=u_{i}(s)$. Next, if $|\mathcal{P}(s)|>6$ and $|I|<2|\mathcal{P}(s)|$, then there exists at least one party $P \in \mathcal{P}(s)$ such that $P=\{i\}$. It follows from Lemma 9 that $u_{i}(s)=\frac{1}{|\mathcal{P}(s)|}$. Let $P^{\prime}$ be the closest party adjacent to $P$ in $s$. We know that $\left|P^{\prime}\right| \in\{1,2\}$ (Lemma 11). If politician $i$ deviates to $s_{i}^{\prime}$, which is the agenda supported by $P^{\prime}$ in $s$, then there are at most two parties with the highest weight in $\left(s_{i}^{\prime}, s_{-i}\right)$ and $P^{\prime} \cup\{i\}$ is one of these two parties. Hence, $u_{i}\left(s_{i}^{\prime}, s_{-i}\right) \geq \frac{1}{2\left(\left|P^{\prime}\right|+1\right)} \geq \frac{1}{6}>\frac{1}{|\mathcal{P}(s)|}$, a contradiction.

Lemma 15. A strategy profile $s$ such that $5 \leq|\mathcal{P}(s)| \leq 6$ and $|I|<2|\mathcal{P}(s)|$ is a Nash equilibrium if and only if all parties are equidistant from each other, $\max _{P, P^{\prime} \in \mathcal{P}(s)}|P|-\left|P^{\prime}\right| \leq$ 1 , and there do not exist $P, P^{\prime} \in \mathcal{P}(s)$ such that $P$ and $P^{\prime}$ are adjacent, and $|P|=\left|P^{\prime}\right|=1$.

Proof. Let $s$ be such a Nash equilibrium. First, suppose that the parties are not equidistant. It follows from Lemma 10 that $|\mathcal{P}(s)|=6$ and $l^{s}\left(P^{\prime \prime}\right) \neq r^{s}\left(P^{\prime \prime}\right)$ for all $P^{\prime \prime} \in \mathcal{P}(s)$. Since $|I|<2|\mathcal{P}(s)|$ there exists a party $P \in \mathcal{P}(s)$ such that $P=\{i\}$. Hence, $u_{i}(s)=\frac{1}{|\mathcal{P}(s)|}$ (Lemma 9). Let $P^{\prime}$ be the closest party adjacent to $P$ in $s$. We know that $\left|P^{\prime}\right| \in\{1,2\}$ (Lemma 11). If politician $i$ deviates to $s_{i}^{\prime}$, which is the agenda supported by $P^{\prime}$ in $s$, then the weight of party $P^{\prime} \cup\{i\}$ in $\left(s_{i}^{\prime}, s_{-i}\right)$ is strictly greater than any other party's weight and hence, $u_{i}\left(s_{i}^{\prime}, s_{-i}\right) \geq \frac{1}{3}>\frac{1}{6}$, a contradiction. Therefore, all parties in $s$ are equidistant from each other.

Next, suppose that there are two adjacent parties $P, P^{\prime} \in \mathcal{P}(s)$ such that $|P|=\left|P^{\prime}\right|=1$. Let $P=\{i\}$. Then $u_{i}(s)=\frac{1}{|\mathcal{P}(s)|}$ (Lemma 9$)$. If politician $i$ deviates to $s_{i}^{\prime}$, which is the agenda supported by $P^{\prime}$ in $s$, then there are exactly two parties in $\left(s_{i}^{\prime}, s_{-i}\right)$ with the highest weight and party $P^{\prime} \cup\{i\}$ in $\left(s_{i}^{\prime}, s_{-i}\right)$ is one of them. Hence, $u_{i}\left(s_{i}^{\prime}, s_{-i}\right)=\frac{1}{4}>\frac{1}{|\mathcal{P}(s)|}$, a contradiction. 
Finally, we show the other implication. Let $s$ satisfy the conditions listed in the lemma. Pick any $P \in \mathcal{P}(s)$ and $i \in P$. Then $|P| \leq 2$ and $u_{i}(s)=\frac{1}{|\mathcal{P}(s)||P|}$. Consider any deviation $s_{i}^{\prime}$ by politician $i$.

(i) Suppose $|P|=2$ : If $s_{i}^{\prime}$ is an agenda supported by some $P^{\prime} \in \mathcal{P}(s)$, then the sets of agendas supported by the parties are the same in $s$ and $\left(s_{i}^{\prime}, s_{-i}\right)$. Hence, $w_{P^{\prime} \cup\{i\}}\left(s_{i}^{\prime}, s_{-i}\right)=$ $w_{P^{\prime}}(s)$ and therefore, $u_{i}\left(s_{i}^{\prime}, s_{-i}\right)=\frac{1}{\mathcal{P}(s) \mid\left(\left|P^{\prime}\right|+1\right)} \leq \frac{1}{\mathcal{P}(s)|| P \mid}$ since $|P| \leq\left|P^{\prime}\right|+1$. If $s_{i}^{\prime}$ is an agenda that is not supported by any party in strategy $s$, then there exists a $P^{\prime} \in \mathcal{P}(s)$ such that $s_{i}^{\prime}$ is between the agendas supported by $P^{\prime}$ and $L^{s}\left(P^{\prime}\right)$ in $s$. Hence, $w_{\{i\}}\left(s_{i}^{\prime}, s_{-i}\right)=\frac{l^{s}\left(P^{\prime}\right)}{2}$. But the weight of party $R^{\left(s_{i}^{\prime}, s_{i}\right)}\left(P^{\prime}\right)$ in $\left(s_{i}^{\prime}, s_{-i}\right)$ equals $\frac{l^{s}\left(P^{\prime}\right)+r^{s}\left(P^{\prime}\right)}{2}$ (using the fact that there are at least three parties in $s$ and all these parties have equal weights). Hence, $u_{i}\left(s_{i}^{\prime}, s_{-i}\right)=0$ and therefore, there is no incentive for her to deviate.

(ii) Suppose $|P|=1$ : Let $\operatorname{arc} d^{\prime}$ be the arc between the agendas supported by $L^{s}(P)$ and $R^{s}(P)$ in $s$ that does not contain $s_{i}$. If $s_{i}^{\prime}$ is in arc $d^{\prime}$ but $s_{i}^{\prime}$ is neither the agenda supported by $L^{s}(P)$ nor $R^{s}(P)$ in $s$, then parties $L^{s}(P)$ and $R^{s}(P)$ are also formed in strategy $\left(s_{i}^{\prime}, s_{-i}\right)$ and at least one of them obtains a higher weight than the party of politician $i$ in $\left(s_{i}^{\prime}, s_{-i}\right)$. Hence, $u_{i}\left(s_{i}^{\prime}, s_{-i}\right)=0$ and therefore, there is no incentive to deviate. If $s_{i}^{\prime}$ is the agenda supported by $L^{s}(P)$ in $s$, then $L^{s}(P) \cup\{i\}$ and $R^{s}(P)$ form in strategy $\left(s_{i}^{\prime}, s_{-i}\right)$ and obtain the highest weight. Since $\left|L^{s}(P)\right|=2$, we have $u_{i}\left(s_{i}^{\prime}, s_{-i}\right)=\frac{1}{6}$. Therefore, there is no incentive to deviate. A similar argument works if $s_{i}^{\prime}$ is the agenda supported by $R^{s}(P)$ in $s$. In the remaining case, $u_{i}\left(s_{i}^{\prime}, s_{-i}\right)=0$ since both $L^{s}(P)$ and $R^{s}(P)$ are also formed in strategy $\left(s_{i}^{\prime}, s_{-i}\right)$ and at least one of them obtains a higher weight than the party of politician $i$ in $\left(s_{i}^{\prime}, s_{-i}\right)$. Hence, there is no incentive to deviate.

Therefore, $s$ is a Nash equilibrium.

Lemma 16. A strategy profile $s$ such that $3 \leq|\mathcal{P}(s)| \leq 4$ and $|I|<2|\mathcal{P}(s)|$ is a Nash equilibrium if and only if all parties are equidistant from each other and $\max _{P, P^{\prime} \in \mathcal{P}(s)}|P|-$ $\left|P^{\prime}\right| \leq 1$

Proof. The proof of this lemma is similar to the proof of Lemma 15.

The above lemmas together imply the characterization in the theorem.

Proof of Theorem 3: We prove the theorem through a series of lemmas.

Lemma 17. Let $s$ be such that $|\mathcal{P}(s)| \geq 4$. Then $s$ is not a defection-proof Nash equilibrium.

Proof. Assume that $s$ is a defection-proof Nash equilibrium. Let $\mathcal{P}(s)=\left\{P^{1}, \ldots, P^{n}\right\}$ such that $n \geq 4$. Without loss of generality, let $P^{k+1}=R^{s}\left(P^{k}\right)$ for all $k=1, \ldots, n-1$ and 
$l^{s}\left(P^{3}\right) \leq r^{s}\left(P^{3}\right)$. Since $s$ is a Nash equilibrium, all parties in $\mathcal{P}(s)$ have equal weights. Therefore, $u_{i}(s)=\frac{1}{|\mathcal{P}(s)|\left|P^{k}\right|}$ for all $i \in P^{k}$. Moreover, $\left|P^{2}\right|+\left|P^{3}\right| \leq 2\left|P^{k}\right|+1$ for $k=2,3$ (using Lemma 11).

Consider the arc between the agendas supported by $P^{2}$ and $P^{3}$ in $s$ corresponding to $l^{s}\left(P^{3}\right)$. Let $a$ be the midpoint of this arc. Consider the coalition $J=P^{2} \cup P^{3}$ and $s_{J}^{\prime}$ such that $s_{j}^{\prime}=a$ for all $j \in J$. Let $s^{\prime}=\left(s_{J}^{\prime}, s_{-J}\right)$. Now, $\mathcal{P}\left(s^{\prime}\right)=\left\{P^{1}, P^{2} \cup P^{3}, P^{4}, \ldots, P^{n}\right\}$ and

$$
l^{s^{\prime}}\left(P^{2} \cup P^{3}\right)=l^{s}\left(P^{2}\right)+\frac{l^{s}\left(P^{3}\right)}{2}=r^{s}\left(P^{3}\right)+\frac{r^{s}\left(P^{2}\right)}{2}=r^{s^{\prime}}\left(P^{2} \cup P^{3}\right) .
$$

Thus, the weight of $P^{2} \cup P^{3}$ in $s^{\prime}$ equals $l^{s}\left(P^{2}\right)+\frac{l^{s}\left(P^{3}\right)}{2}$. Now, $r^{s^{\prime}}\left(P^{1}\right)=l^{s^{\prime}}\left(P^{2} \cup P^{3}\right)$ and $l^{s^{\prime}}\left(P^{1}\right)=l^{s}\left(P^{1}\right)=l^{s}\left(P^{3}\right) \leq r^{s}\left(P^{3}\right)=l^{s}\left(P^{2}\right)$. Similarly, $l^{s^{\prime}}\left(P^{4}\right)=r^{s^{\prime}}\left(P^{2} \cup P^{3}\right)$ and $r^{s^{\prime}}\left(P^{4}\right) \leq r^{s}\left(P^{3}\right)$. Therefore, in $s^{\prime}, P^{2} \cup P^{3}$ has a greater weight than both $P^{1}$ and $P^{4}$. Clearly, $w_{P^{k}}\left(s^{\prime}\right)=w_{P^{k}}(s)$ for all $k>4$. Therefore, in $s^{\prime}, P^{2} \cup P^{3}$ is the unique party with the maximum weight. Hence, $u_{j}\left(s^{\prime}\right)=\frac{1}{\left|P^{2}\right|+\mid P^{3}}$ for all $j \in J$.

Since $|\mathcal{P}(s)|\left|P^{k}\right| \geq 4\left|P^{k}\right|>2\left|P^{k}\right|+1 \geq\left|P^{2}\right|+\left|P^{3}\right|$ for $k=2,3, s_{J}^{\prime}$ is a defection from $s$ by $J$.

Consider any subcoalition $J^{\prime} \subset J$ and let $s_{J^{\prime}}^{\prime \prime}$ be such that $s_{j}^{\prime \prime}=a^{\prime} \neq a$ for all $j \in J^{\prime \prime}$. Let $s^{\prime \prime}=\left(s_{J^{\prime}}^{\prime \prime}, s_{-J^{\prime}}^{\prime}\right)$. If $a^{\prime}$ lies on the arc between the agendas supported by $P^{1}$ and $P^{4}$ in $s^{\prime}$ that does not contain $a$, then party $J \backslash J^{\prime}$ will be the unique party with the maximum weight in $s^{\prime \prime}$. Hence, the utility of each $j \in J^{\prime \prime}$ will be zero in $s^{\prime \prime}$. In all other cases, the new party $J^{\prime}$ will obtain a weight of $\frac{l^{s^{\prime}}\left(P^{2} \cup P^{3}\right)}{2}$, which is less than the weight obtained by at least either $P^{1}$ or $P^{4}$ in $s^{\prime \prime}$. Thus, the utility of each $j \in J^{\prime \prime}$ will again be zero in $s^{\prime \prime}$. So there does not exist any subcoalition $J^{\prime} \subset J$ with a defection from $s^{\prime}$. Therefore, $s_{J}^{\prime}$ is a credible defection from $s$ by $J$, a contradiction.

Lemma 18. Let $s$ be a Nash equilibrium such that $|\mathcal{P}(s)|=3$. Then, $s$ is a defection-proof Nash equilibrium.

Proof. Let $\mathcal{P}(s)=\left\{P^{1}, P^{2}, P^{3}\right\}, J$ a coalition of politicians, and $s_{J}^{\prime}$ a profile for this coalition such that $s_{j} \neq s_{j}^{\prime}=a$ for all $j \in J$. Suppose $s_{J}^{\prime}$ is a credible defection from $s$ by $J$. Consider the following cases:

(i) $P^{k} \backslash J \neq \emptyset$ for all $k \in\{1,2,3\}$. Pick any $j \in J$ and consider the strategy profile $\left(s_{j}^{\prime}, s_{-j}\right)$. Clearly the set of agendas supported in $\left(s_{J}^{\prime}, s_{-J}\right)$ is equal to the set of agendas supported in $\left(s_{j}^{\prime}, s_{-j}\right)$. Therefore, the weight of party supporting $a$ in $\left(s_{J}^{\prime}, s_{-J}\right)$ is equal to the weight of the party supporting $a$ in $\left(s_{j}^{\prime}, s_{-j}\right)$. But the latter party is singleton. Thus, $u_{j}\left(s_{j}^{\prime}, s_{-j}\right) \geq u_{j}\left(s_{J}^{\prime}, s_{-J}\right)>u_{j}(s)$, a contradiction to the fact that $s$ is a Nash equilibrium.

(ii) $P^{1} \subseteq J$ and $P^{k} \backslash J \neq \emptyset$ for $k=2,3$. Then $a$ is not supported by $P^{1}$ in $s$. If $a$ is also not supported by $P^{2}$ or $P^{3}$ in $s$, then three parties form in $\left(s_{J}^{\prime}, s_{-J}\right)$ but the weight of the party supporting $a$ is less than the weight of at least one other party. Thus, $u_{j}\left(s_{J}^{\prime}, s_{-J}\right)=0$ for all 
$j \in J$, a contradiction. If $a$ is supported by, without loss of generality, $P^{2}$, then $P^{2} \cap J=\emptyset$. Now, two parties form in $\left(s_{J}^{\prime}, s_{-J}\right)$. Pick any $j \in P^{1}$. Then $u_{j}\left(s_{J}^{\prime}, s_{-J}\right) \leq \frac{1}{2\left|P^{1}\right|+2\left|P^{2}\right|}$. On the other hand, $u_{j}(s)=\frac{1}{3\left|P^{1}\right|}$. However, $3\left|P^{1}\right| \leq 2\left|P^{1}\right|+2\left|P^{2}\right|$ because $\left|P^{1}\right| \leq\left|P^{2}\right|+1 \leq 2\left|P^{2}\right|$. So $s_{J}^{\prime}$ cannot be a defection. Similarly, we can obtain contradictions when either:

(iii) $P^{2} \subseteq J$ and $P^{k} \backslash J \neq \emptyset$ for $k=1,3$, or

(iv) $P^{3} \subseteq J$ and $P^{k} \backslash J \neq \emptyset$ for $k=1,2$.

(v) $P^{1} \cup P^{2} \subseteq J$ and $P^{3} \backslash J \neq \emptyset$. Then $a$ is not supported by both $P^{1}$ and $P^{2}$ in $s$. If $a$ is also not supported by $P^{3}$ in $s$, then two parties form in $\left(s_{J}^{\prime}, s_{-J}\right)$. Pick any $j \in P^{1}$. Then $u_{j}\left(s_{J}^{\prime}, s_{-J}\right) \leq \frac{1}{2\left|P^{1}\right|+2\left|P^{2}\right|}$. On the other hand, $u_{j}(s)=\frac{1}{3\left|P^{1}\right|}$. However, as above, $3\left|P^{1}\right| \leq 2\left|P^{1}\right|+2\left|P^{2}\right|$. So $s_{J}^{\prime}$ cannot be a defection, a contradiction. If $a$ is supported by $P^{3}$, then $P^{3} \cap J=\emptyset$. Now, a single party is formed in $\left(s_{J}^{\prime}, s_{-J}\right)$. However, since $\left(s_{J}^{\prime}, s_{-J}\right)$ is not a Nash equilibrium, there exists a credible defection by a single politician, without loss of generality by $j \in J$, from $\left(s_{J}^{\prime}, s_{-J}\right)$. Thus, $\left(s_{J}^{\prime}, s_{-J}\right)$ is not a credible defection from $s$ by $J$, a contradiction. We can similarly obtain contradictions when either:

(vi) $P^{1} \cup P^{3} \subseteq J$ and $P^{2} \backslash J \neq \emptyset$, or

(vii) $P^{2} \cup P^{3} \subseteq J$ and $P^{1} \backslash J \neq \emptyset$.

(viii) $P^{1} \cup P^{2} \cup P^{3}=J$. A single party is formed after the defection and hence, the resulting profile is not a Nash equilibrium. Thus, the initial defection is not credible, a contradiction.

Lemma 19. Let $s$ be a Nash equilibrium such that $|\mathcal{P}(s)|=2$. Then $s$ is a defection-proof Nash equilibrium.

Proof. Let $\mathcal{P}(s)=\left\{P^{1}, P^{2}\right\}, J$ a coalition of politicians, and $s_{J}^{\prime}$ a profile for this coalition such that $s_{j} \neq s_{j}^{\prime}=a$ for all $j \in J$. Suppose $s_{J}^{\prime}$ is a credible defection from $s$ by $J$. Consider the following cases:

(i) $P^{k} \backslash J \neq \emptyset$ for all $k \in\{1,2\}$. Pick any $j \in J$ and consider the strategy profile $\left(s_{j}^{\prime}, s_{-j}\right)$. Clearly the set of agendas supported in $\left(s_{J}^{\prime}, s_{-J}\right)$ is equal to the set of agendas supported in $\left(s_{j}^{\prime}, s_{-j}\right)$. Therefore, the weight of party supporting $a$ in $\left(s_{J}^{\prime}, s_{-J}\right)$ is equal to the weight of the party supporting $a$ in $\left(s_{j}^{\prime}, s_{-j}\right)$. But the latter party is singleton. Thus, $u_{j}\left(s_{j}^{\prime}, s_{-j}\right) \geq u_{j}\left(s_{J}^{\prime}, s_{-J}\right)>u_{j}(s)$, a contradiction to the fact that $s$ is a Nash equilibrium.

(ii) $P^{1} \subseteq J$ and $P^{2} \backslash J \neq \emptyset$. Then $a$ is not supported by $P^{1}$ in $s$. If $a$ is also not supported by $P^{2}$ in $s$, then two parties form in $\left(s_{J}^{\prime}, s_{-J}\right)$. The weight of the party supporting $a$ is equal to $\frac{1}{2}$. Thus, for any $j \in P^{1}$, we have $u_{j}\left(s_{J}^{\prime}, s_{-J}\right) \leq \frac{1}{2\left|P^{1}\right|}=u_{j}(s)$, a contradiction. If $a$ is supported by $P^{2}$, then $P^{2} \cap J=\emptyset$. Now, a single party is formed in $\left(s_{J}^{\prime}, s_{-J}\right)$. However, since $\left(s_{J}^{\prime}, s_{-J}\right)$ is not a Nash equilibrium, $\left(s_{J}^{\prime}, s_{-J}\right)$ is not a credible defection from $s$ by $J$, a contradiction. We can similarly obtain a contradiction when:

(iii) $P^{2} \subseteq J$ and $P^{1} \backslash J \neq \emptyset$. 
(iv) $P^{1} \cup P^{2}=J$. A single party is formed after the defection and hence, the resulting profile is not a Nash equilibrium. Thus, the initial defection is not credible, a contradiction.

These lemmas together imply the characterization in the theorem.

\subsection{Proportional Rule}

Proof of Theorem 5: We prove the theorem through a series of lemmas.

Lemma 20. Let $s$ be such that there exists a party $P$ in $\mathcal{P}(s)$ with $|P| \geq 3$. Then $s$ is not a Nash equilibrium.

Proof. Let $P \in \mathcal{P}(s)$ such that $|P| \geq 3$. Without loss of generality, suppose $l^{s}(P) \geq r^{s}(P)$. Pick any politician $i \in P$ and consider the strategy profile $\left(s_{i}^{\prime}, s_{-i}\right)$ such that $s_{i}^{\prime}$ is any agenda on the arc corresponding to $l^{s}(P)$ except the agendas supported by $P$ and $L^{s}(P)$ in $s$. Then $u_{i}\left(s_{i}^{\prime}, s_{-i}\right)=\frac{l^{s}(P)}{2}>\frac{l^{s}(P)}{|P|} \geq \frac{l^{s}(P)+r^{s}(P)}{2|P|}=u_{i}(s)$. Therefore, $s$ is not a Nash equilibrium.

Lemma 21. Let $s$ be a Nash equilibrium. Then for any $P \in \mathcal{P}(s)$ such that $|P|=2$, we must have $l^{s}(P)=r^{s}(P)=\max _{P^{\prime} \in \mathcal{P}(s)}\left\{l^{s}\left(P^{\prime}\right), r^{s}\left(P^{\prime}\right)\right\}$.

Proof. Let $P \in \mathcal{P}(s)$ such that $|P|=2$. Let $d^{*}=\max _{P^{\prime} \in \mathcal{P}(s)}\left\{l^{s}\left(P^{\prime}\right), r^{s}\left(P^{\prime}\right)\right\}$. Suppose $d^{*}>\min \left\{l^{s}(P), r^{s}(P)\right\}$. Note that $d^{*} \geq \max \left\{l^{s}(P), r^{s}(P)\right\}$. Therefore, $\frac{l^{s}(P)+r^{s}(P)}{2}<d^{*}$. Let $P^{\prime \prime}=\arg \max _{P^{\prime} \in \mathcal{P}(s)}\left\{l^{s}\left(P^{\prime}\right), r^{s}\left(P^{\prime}\right)\right\}$ and without loss of generality, suppose $l^{s}\left(P^{\prime \prime}\right) \geq r^{s}\left(P^{\prime \prime}\right)$. Pick any politician $i \in P$ and consider the strategy profile $\left(s_{i}^{\prime \prime}, s_{-i}\right)$ such that $s_{i}^{\prime \prime}$ is any agenda on the arc corresponding to $l^{s}\left(P^{\prime \prime}\right)$ except the agendas supported by $P^{\prime \prime}$ and $L^{s}\left(P^{\prime \prime}\right)$ in $s$. Then $u_{i}\left(s_{i}^{\prime \prime}, s_{-i}\right)=\frac{l^{s}\left(P^{\prime \prime}\right)}{2}=\frac{d^{*}}{2}>\frac{l^{s}(P)+r^{s}(P)}{4}=u_{i}(s)$. Therefore, $s$ is not a Nash equilibrium.

Lemma 22. Let $s$ be a Nash equilibrium. Then for any $P \in \mathcal{P}(s)$ such that $|P|=1$, we must have $l^{s}(P)+r^{s}(P) \geq \max _{P^{\prime} \in \mathcal{P}(s)}\left\{l^{s}\left(P^{\prime}\right), r^{s}\left(P^{\prime}\right)\right\}$.

Proof. Let $P \in \mathcal{P}(s)$ such that $|P|=1$. Suppose $l^{s}(P)+r^{s}(P)<\max _{P^{\prime} \in \mathcal{P}(s)}\left\{l^{s}\left(P^{\prime}\right), r^{s}\left(P^{\prime}\right)\right\}$. Let $P^{\prime \prime}=\arg \max _{P^{\prime} \in \mathcal{P}(s)}\left\{l^{s}\left(P^{\prime}\right), r^{s}\left(P^{\prime}\right)\right\}$ and without loss of generality, suppose $l^{s}\left(P^{\prime \prime}\right) \geq$ $r^{s}\left(P^{\prime \prime}\right)$. Pick any politician $i \in P$ and consider the strategy profile $\left(s_{i}^{\prime \prime}, s_{-i}\right)$ such that $s_{i}^{\prime \prime}$ is any agenda on the arc corresponding to $l^{s}\left(P^{\prime \prime}\right)$ except the agendas supported by $P^{\prime \prime}$ and $L^{s}\left(P^{\prime \prime}\right)$ in $s$. Then $u_{i}\left(s_{i}^{\prime \prime}, s_{-i}\right)=\frac{l^{s}\left(P^{\prime \prime}\right)}{2}>\frac{l^{s}(P)+r^{s}(P)}{2}=u_{i}(s)$. Therefore, $s$ is not a Nash equilibrium.

Lemma 23. Let $s$ be such that for any party $P \in \mathcal{P}(s)$ either

(i) $|P|=2$ and $l^{s}(P)=r^{s}(P)=\max _{P^{\prime} \in \mathcal{P}(s)}\left\{l^{s}\left(P^{\prime}\right), r^{s}\left(P^{\prime}\right)\right\}$ or

(ii) $|P|=1$ and $l^{s}(P)+r^{s}(P) \geq \max _{P^{\prime} \in \mathcal{P}(s)}\left\{l^{s}\left(P^{\prime}\right), r^{s}\left(P^{\prime}\right)\right\}$.

Then $s$ is a Nash equilibrium. 
Proof. Let $s$ be such a strategy profile and $d^{*}=\max _{P^{\prime} \in \mathcal{P}(s)}\left\{l^{s}\left(P^{\prime}\right), r^{s}\left(P^{\prime}\right)\right\}$. Pick a $P \in \mathcal{P}(s)$ such that $|P|=2$. A politician $i$ in party $P$ gets $\frac{d^{*}}{2}$. Consider a deviation $s_{i}^{\prime}$. First, suppose $s_{i}^{\prime}$ is not an agenda supported in $s$. Clearly, $s_{i}^{\prime}$ lies between two agendas supported in $s$. Furthermore, since $|P|=2$, all the agendas that are supported in $s$ are also supported in $\left(s_{i}^{\prime}, s_{-i}\right)$. Hence, there exists a $P^{\prime \prime} \in \mathcal{P}(s)$ such that $u_{i}\left(s_{i}^{\prime}, s_{-i}\right)=\frac{l^{s}\left(P^{\prime \prime}\right)}{2} \leq \frac{d^{*}}{2}=u_{i}(s)$. Second, suppose $s_{i}^{\prime}$ is an agenda supported in $s$ by $P^{\prime \prime}$ such that $\left|P^{\prime \prime}\right|=2$. Now, the set of agendas supported in $\left(s_{i}^{\prime}, s_{-i}\right)$ equals the set of agendas supported in $s$. Clearly, $u_{i}\left(s_{i}^{\prime}, s_{-i}\right)=\frac{d^{*}}{3}<$ $u_{i}(s)$. Finally, suppose $s_{i}^{\prime}$ is an agenda supported in $s$ by $P^{\prime \prime}$ such that $\left|P^{\prime \prime}\right|=1$. Again, the set of agendas supported in $\left(s_{i}^{\prime}, s_{-i}\right)$ equals the set of agendas supported in $s$. Moreover, $u_{i}\left(s_{i}^{\prime}, s_{-i}\right)=\frac{l^{s}\left(P^{\prime \prime}\right)+r^{s}\left(P^{\prime \prime}\right)}{4} \leq \frac{d^{*}}{2}=u_{i}(s)$.

Next, pick a $P \in \mathcal{P}(s)$ such that $|P|=1$. Since $l^{s}(P)+r^{s}(P) \geq d^{*}$, the politician $i$ in party $P$ gets utility of at least $\frac{d^{*}}{2}$. Consider a deviation $s_{i}^{\prime}$. First, suppose $s_{i}^{\prime}$ is not an agenda supported in $s$. If $s_{i}^{\prime}$ does not lie on the arc between the agendas supported by $L^{s}(P)$ and $R^{s}(P)$ that contains $s_{i}$, then there exists a $P^{\prime \prime} \in \mathcal{P}(s)$ such that $u_{i}\left(s_{i}^{\prime}, s_{-i}\right)=\frac{l^{s}\left(P^{\prime \prime}\right)}{2} \leq \frac{d^{*}}{2} \leq$ $u_{i}(s)$. On the other hand, if $s_{i}^{\prime}$ lies on the arc between the agendas supported by $L^{s}(P)$ and $R^{s}(P)$ that contains $s_{i}$, then $u_{i}\left(s_{i}^{\prime}, s_{-i}\right)=u_{i}(s)$. Second, suppose $s_{i}^{\prime}$ is an agenda supported in $s$ by $P^{\prime \prime}$ such that $\left|P^{\prime \prime}\right|=2$. If $P^{\prime \prime} \notin\left\{L^{s}(P), R^{s}(P)\right\}$, then $u_{i}\left(s_{i}^{\prime}, s_{-i}\right)=\frac{d^{*}}{3}<\frac{d^{*}}{2} \leq u_{i}(s)$. On the other hand, if $P^{\prime \prime}=L^{s}(P)$ (a similar argument works when $P^{\prime \prime}=R^{s}(P)$ ), then $u_{i}\left(s_{i}^{\prime}, s_{-i}\right)=\frac{l^{s}\left(P^{\prime \prime}\right)+l^{s}(P)+r^{s}(P)}{6} \leq \frac{d^{*}}{2} \leq u_{i}(s)$. Finally, suppose $s_{i}^{\prime}$ is an agenda supported in $s$ by $P^{\prime \prime}$ such that $\left|P^{\prime \prime}\right|=1$. If $P^{\prime \prime} \notin\left\{L^{s}(P), R^{s}(P)\right\}$, then $u_{i}\left(s_{i}^{\prime}, s_{-i}\right) \leq \frac{d^{*}}{2} \leq u_{i}(s)$. On the other hand, if $P^{\prime \prime}=L^{s}(P)$ (a similar argument works when $P^{\prime \prime}=R^{s}(P)$ ), then $u_{i}\left(s_{i}^{\prime}, s_{-i}\right)=\frac{l^{s}\left(P^{\prime \prime}\right)+l^{s}(P)+r^{s}(P)}{4} \leq \frac{d^{*}+l^{s}(P)+r^{s}(P)}{4} \leq \frac{l^{s}(P)+r^{s}(P)}{2}=u_{i}(s)$.

Therefore, $s$ is a Nash equilibrium.

These lemmas together imply the characterization in the theorem.

Proof of Theorem 7: Every defection-proof Nash equilibrium is by definition a Nash equilibrium.

Suppose $s$ is a Nash equilibrium. Let $J$ be a coalition of politicians, and $s_{J}^{\prime}$ a profile for this coalition such that $s_{j} \neq s_{j}^{\prime}=a$ for all $j \in J$. Suppose $s_{J}^{\prime}$ is a credible defection from $s$ by $J$.

Since $s$ is a Nash equilibrium, we must have $|J| \geq 2$. Consider the profile $s^{\prime}=\left(s_{J}^{\prime}, s_{-J}\right)$ and let $P \in \mathcal{P}\left(s^{\prime}\right)$ be such that $J \subseteq P$.

First, suppose $|P| \geq 3$. Without loss of generality, let $l^{s^{\prime}}(P) \geq r^{s^{\prime}}(P)$. Pick any politician $j \in J$ and consider the strategy profile $\left(s_{j}^{\prime \prime}, s_{-j}^{\prime}\right)$ such that $s_{j}^{\prime \prime}$ is any agenda on the arc corresponding to $l^{s^{\prime}}(P)$ except the agendas supported by $P$ and $L^{s^{\prime}}(P)$ in $s^{\prime}$. Then $u_{j}\left(s_{j}^{\prime \prime}, s_{-j}^{\prime}\right)=\frac{l^{s^{\prime}}(P)}{2}>\frac{l^{s^{\prime}}(P)}{|P|} \geq \frac{l^{s^{\prime}}(P)+r^{s^{\prime}}(P)}{2|P|}=u_{j}\left(s^{\prime}\right)$. Therefore, $s_{j}^{\prime \prime}$ is a credible defection from $s^{\prime}$ by $j \in J$; a contradiction. Thus, it must be that $|P|=|J|=2$. Therefore, $a$ is not 
supported by any party in $s$ and hence, $a$ lies between the agendas supported by some $P^{\prime}$ and $L^{s}\left(P^{\prime}\right)$ in $s$. Consider the following cases:

(i) Suppose $P^{\prime} \backslash J \neq \emptyset$ and $L^{s}\left(P^{\prime}\right) \backslash J \neq \emptyset$. Pick any $j \in J$. Then $u_{j}\left(s^{\prime}\right)=\frac{l^{s}\left(P^{\prime}\right)}{2}$. Since $s_{J}^{\prime}$ is a defection from $s$ by $J$, it must be that $u_{j}\left(s^{\prime}\right)>u_{j}(s)$. Consider the strategy profile $\left(s_{j}^{\prime}, s_{-j}\right)$. Clearly, $u_{j}\left(s_{j}^{\prime}, s_{-j}\right)=\frac{l^{s}\left(P^{\prime}\right)}{2}>u_{j}(s)$, a contradiction to the fact that $s$ is a Nash equilibrium.

(ii) Suppose $P^{\prime} \subseteq J$ and $L^{s}\left(P^{\prime}\right) \backslash J \neq \emptyset$. If $R^{s}\left(P^{\prime}\right) \backslash J \neq \emptyset$, then for any $j \in J \cap P^{\prime}$ we have $u_{j}\left(s^{\prime}\right)=\frac{l^{s}\left(P^{\prime}\right)+r^{s}\left(P^{\prime}\right)}{4} \leq u_{j}(s)$ (the equality uses the fact that $|J|=2$ ). On the other hand, if $R^{s}\left(P^{\prime}\right) \subseteq J$, then $P^{\prime} \cup R^{s}\left(P^{\prime}\right) \subseteq J$ and $|J|=2$ implies that $P^{\prime} \cup R^{s}\left(P^{\prime}\right)=J$. Let $P^{\prime \prime}=R^{s}\left(P^{\prime}\right)$. Since $P^{\prime} \cup R^{s}\left(P^{\prime}\right)=J$, both parties $L^{s}\left(P^{\prime}\right)$ and $R^{s}\left(P^{\prime \prime}\right)$ form in $s^{\prime}$. Moreover, since $s$ is a Nash equilibrium and $\left|P^{\prime}\right|=1$, we have $r^{s}\left(P^{\prime \prime}\right) \leq l^{s}\left(P^{\prime}\right)+r^{s}\left(P^{\prime}\right)$. Thus, for $j \in P^{\prime}$, $u_{j}\left(s^{\prime}\right)=\frac{l^{s}\left(P^{\prime}\right)+r^{s}\left(P^{\prime}\right)+r^{s}\left(P^{\prime \prime}\right)}{4} \leq \frac{l^{s}\left(P^{\prime}\right)+r^{s}\left(P^{\prime}\right)}{2}=u_{j}(s)$, a contradiction. We can similarly obtain a contradiction when:

(iii) $P^{\prime} \backslash J \neq \emptyset$ and $L^{s}\left(P^{\prime}\right) \subseteq J$.

(iv) Suppose $P^{\prime} \subseteq J$ and $L^{s}\left(P^{\prime}\right) \subseteq J$. Let $P^{\prime \prime}=L^{s}\left(P^{\prime}\right)$. Then $P^{\prime} \cup P^{\prime \prime}=J$ since $|J|=2$. Moreover both parties $L^{s}\left(P^{\prime \prime}\right)$ and $R^{s}\left(P^{\prime}\right)$ form in $s^{\prime}$ (these parties exist since $|I| \geq 3>|J|$ ). Since $s$ is a Nash equilibrium and $\left|P^{\prime}\right|=1$, we have $l^{s}\left(P^{\prime \prime}\right) \leq l^{s}\left(P^{\prime}\right)+r^{s}\left(P^{\prime}\right)$. Thus, for $j \in P^{\prime}$, $u_{j}\left(s^{\prime}\right)=\frac{l^{s}\left(P^{\prime \prime}\right)+l^{s}\left(P^{\prime}\right)+r^{s}\left(P^{\prime}\right)}{4} \leq \frac{l^{s}\left(P^{\prime}\right)+r^{s}\left(P^{\prime}\right)}{2}=u_{j}(s)$, a contradiction.

\section{References}

[1] Bernheim B, B Peleg and M Whinston (1987). Coalition-proof Nash equilibria I: Concepts. Journal of Economic Theory 42 (1): 1-12.

[2] Besley T and S Coate (1997). An economic model of representative democracy. Quarterly Journal of Economics 112 (1): 85-114.

[3] Cox G (1987). Electoral equilibrium under alternative voting institutions. American Journal of Political Science 31 (1): 82-108.

[4] Downs A (1957). An Economic Theory of Democracy. New York: Harper and Row.

[5] Duverger M (1954). Political Parties. New York: Wiley.

[6] Feddersen T (1992). A voting model implying Duverger's law and positive turnout. American Journal of Political Science 36 (4): 938-62.

[7] Fey M (1997). Stability and coordination in Duverger's law: A formal model of preelection polls and strategic voting. American Political Science Review 91 (1): 135-147.

[8] Gupta B, F-C Lai, D Pal, J Sarkar and C-M Yu (2004). Where to locate in a circular city? International Journal of Industrial Organization 22 (6): 759-782. 
[9] Hotelling H (1929). Stability in competition. Economic Journal 39 (153): 41-57.

[10] Jackson M and B Moselle (2002). Coalition and party formation in a legislative voting game. Journal of Economic Theory 103 (1): 49-87.

[11] Kaminski M (2006). A general equilibrium model of multi-party competition. Social Choice and Welfare 26 (2): 333-361.

[12] Levy G (2004). A model of political parties. Journal of Economic Theory 115 (2): 250277.

[13] Lijphart A (1990). The political consequences of electoral laws, 1945-85. American Political Science Review 84 (2): 481-496.

[14] Morelli M (2004). Party formation and policy outcomes under different electoral systems. Review of Economic Studies 71 (3): 829-853.

[15] Osborne M and A Slivinski (1996). A model of political competition with citizencandidates. Quarterly Journal of Economics 111 (1): 65-96.

[16] Osborne M and R Tourky (2008). Party formation in single-issue politics. Journal of the European Economic Association 6 (5): 974-1005.

[17] Palfrey T (1989). A mathematical proof of Duverger's law. In: Ordeshook P (ed.) Models of Strategic Choice in Politics. Ann Arbor: University of Michigan Press: pp.69-91.

[18] Persson T and G Tabellini (2000). Political Economics: Explaining Economic Policy. Cambridge: MIT Press.

[19] Rae D (1971). The Political Consequences of Electoral Laws (2nd edition). New Haven: Yale University Press.

[20] Riker W (1982). The two-party system and Duverger's law: An essay on the history of political science. American Political Science Review 76 (4): 753-766.

[21] Rivière A (1998). Citizen candidacy, party formation, and Duverger's law. Mimeo: Université Libre de Bruxelles.

[22] Salop S (1979). Monopolistic competition with outside goods. The Bell Journal of Economics 10 (1): 141-156.

[23] Snyder J Jr. and M Ting (2002). An informational rationale for political parties. American Journal of Political Science 46 (1): 90-110.

[24] Taagepera R and M Shugart (1989). Seats and Votes: The Effects and Determinants of Electoral Systems. New Haven: Yale University Press. 